\title{
Yeast Stress Response and Fermentation Efficiency: How to Survive the Making of Wine - A Review
}

\author{
F.F. Bauer and I.S. Pretorius \\ Institute for Wine Biotechnology and Department of Viticulture \& Oenology, University of Stellenbosch, Private Bag X1, 7602 \\ Matieland (Stellenbosch), South Africa \\ Submitted for publication: July 2000 \\ Accepted for publication: August 2000 \\ Key words: Saccharomyces cerevisiae, wine fermentation, yeast resilience, stress response, signal transduction
}

Fermentation predictability and wine quality are directly dependent on wine yeast attributes that assist in the rapid establishment of numerical dominance in the early phase of wine fermentation, and that determine the ability to conduct an even and efficient fermentation to obtain a desirable alcohol degree. It is therefore not surprising that the primary selection criteria applied to most wine yeast strain development programmes relate to the overall objective of achieving an efficient conversion of grape sugar to alcohol and carbon dioxide, at a controlled rate and without the development of off-flavours. Numerous factors influence the fermentation performance of wine yeast. Following a successful inoculation of grape must with an appropriate starter culture strain, the ability of a wine yeast to adapt to and cope with the hostile environment and stress conditions prevailing in grape juice fermentation are of vital importance to fermentation performance. There is a direct correlation between fermentation efficiency and stress resistance, which refers to the ability of a yeast strain to adapt efficiently to a changing environment and unfavourable growth conditions. Successful yeast cellular adaptation to changes in extracellular parameters during wine fermentation requires the timely perception (sensing) of chemical or physical environmental parameters, followed by accurate transmission of the information to the relevant compartments of the cell. Chemical parameters perceived during wine fermentation include the availability/concentration of certain nutrients (e.g., fermentable sugars, assimilable nitrogen, oxygen, vitamins, minerals, ergosterol and unsaturated fatty acids) and the presence of inhibitory substances (e.g., ethanol, acetic acid, fatty acids, sulfite, phenolic phytoalexins, mycotoxins, bacterial toxins and agrochemical residues). Signals of a physical nature include temperature, $\mathrm{pH}$, agitation and osmotic pressure. The sensing of these environmental signals is carried out by specific receptor proteins, most of them situated on the cellular surface. Once perceived, the information is transmitted by a network of dedicated, interconnected signal transduction pathways to the relevant cellular compartments which implement the adaptive response, a process referred to as "stress response". Intensive research has focused on elucidating the molecular mechanisms involved in stress responses, which are evolutionarily well conserved. Besides furthering our understanding of the fundamental strategies for adaptation to hostile, industrial environments, and the biological resilience of Saccharomyces cerevisiae, the data are of key importance to the future improvement of wine yeast strains. This review describes the different types of stress experienced by wine yeast cells during their life cycles, summarises our current knowledge of some of the most important molecular processes required for the survival of the yeast cell, and highlights the potential benefits for future yeast strain development which can be derived from this research.

\section{INTRODUCTION}

Fermentation is broadly defined as the chemical transformation of food-stuff by microorganisms. Archeological evidence suggests that several forms of fermentation have been used by humans for at least several thousand years, and alcoholic fermentation in particular probably represent the oldest form of a biotechnological application of a microorganism (Samuel, 1996). Over the millennia, fermentation technology has been adapted to local conditions and for specific purposes. Alcoholic fermentation, the conversion of sugar, in particular hexoses, into alcohol and $\mathrm{CO}_{2}$, relies almost exclusively on yeast, and several species have been and are used for this purpose. The most commonly encountered species is Saccharomyces cerevisiae, different strains of which are known as baker's, brewer's or wine yeast.

Industrial $S$. cerevisiae strains are highly specialised organisms, which have evolved to utilise to their full potential the different environments or ecological niches that have been provided by human activity. This selection process can be described as "domestication", analogous to the selection process of agricultural plants and mammals, and the $S$. cerevisiae strains used today in bakeries, breweries, wine cellars and other processing facilities probably have little in common with the original yeast that many thousands of years ago started to transform sugar into alcohol inside human-made containers.

Alcoholic fermentation is a dynamic process during which the human-provided "environment", mainly fruit juices or sugars 
extracted from cereals, undergoes continuous changes, which are due to external physical factors and the biological activity of the fermenting organisms. While the external environment is continually changing, organisms must maintain the intracellular physical and chemical parameters within specific limits in order to achieve optimal conditions for metabolic activity. As unicellular organisms, yeast are directly exposed to the environment, unlike cells in complex metazoans, which can maintain close-to-optimal conditions within the organism as a whole. Unicellular organisms therefore have evolved a number of mechanisms allowing them to perceive changes in the surrounding environment and to rapidly adapt to those changes in order to maintain the integrity of the cell and its metabolic activity. Extreme conditions or the failure to adapt will lead either to cell death or to reduced growth, depending on the severity of the condition experienced. For example, the sudden exposure to heat $\left(50^{\circ} \mathrm{C}\right)$ of an exponentially growing culture of $S$. cerevisiae will lead to cell death in a first order process, while exposure to less extreme conditions $\left(37^{\circ} \mathrm{C}\right)$ will lead to a transient growth arrest, which is part of an adaptive response, followed by the resumption of growth (Piper, 1997). Besides the response to temperature, other parameters which require specific adaptations to ensure cellular growth and survival include the availability of nutrients, the osmotic pressure and the $\mathrm{pH}$ of the growth substrate, as well as the presence of high concentrations of growth-inhibiting or toxic compounds like ethanol and salts (Mager \& Hohmann, 1997).

A number of molecular pathways have evolved which ensure that the yeast cell can implement a specific response to changes occurring in those parameters. In a rather broad definition, all environmental changes that elicit such an adaptive response are qualified by the anthropocentric term of "stress". Consequently, the molecular and physiological response of an organism to changes in the environment is referred to as "stress response", while the ability to withstand unfavourable or changing external conditions is defined as "stress resistance" or "stress tolerance". Furthermore, observations of several organisms, including $S$. cerevisiae, have revealed that exposure to a mild stress results in improved resistance to subsequent exposures either to more extreme forms of the same stress or to other stresses, phenomena which have been defined as "acquired stress resistance" and "cross protection", respectively (Ruis \& Schüller, 1995; Siderius \& Mager, 1997).

The inherent biological resilience and stress resistance of wine yeast strains are of especially high interest to winemakers since some of the most vexing problems of wine production, particularly stuck or sluggish fermentation and the production of offflavours by the yeast, are usually associated with the inability of yeast strains to respond and adapt to unfavourable, stressful growth conditions (Attfield, 1997; Henschke, 1998; Bisson, 1999). Data obtained from wine-related studies clearly show an inverse correlation between the inherent stress resistance of specific strains and the frequency with which stuck or sluggish fermentation occurs (Ivorra et al., 1999). As mentioned, stress conditions lead to a reduction in growth speed and survival rate, and therefore always reduce fermentation efficiency. However, the better and faster a yeast strain is able to adapt to changes in the environment, the faster fermentation will be completed. Industrial yeast strains therefore should possess high stress resis- tance; in other words, they must have a good ability to adapt to environmental changes in order to avoid fermentation problems (Attfield, 1997). The making of top quality wine is not only stressful to the winemaker, but is a challenge to the yeast strain as well.

As a consequence, the development of new yeast strains has to take into account the ability of strains to withstand those stress conditions most frequently associated with grape must fermentation. Some of these conditions, as well as the cellular and molecular response of the cell to these conditions, have been intensively studied in a fundamental, wine fermentation-unrelated research context. Most scientific research focuses on furthering our general understanding of cellular adaptation and stress resistance, and relatively little attention has been paid to the specific conditions prevailing during wine fermentation. Nevertheless, the fundamental studies have analysed situations which are also encountered by wine yeast during their life cycle, and the results of this research can therefore be applied to improve the understanding of wine fermentation and fermentation-associated problems. The best-studied stress responses include: (i) the temperature (heat or cold) shock stress response; (ii) the response to the limitation of essential nutrients; (iii) responses to changes in osmotic pressure (hyper- or hypoosmotic shock); and (iv) ethanol toxicity, all of which are of obvious importance during fermentation.

This review summarises current understanding of the most relevant aspects of the molecular mechanisms that allow yeast cells to adapt to changing environmental conditions, and in particular to those stress conditions that are commonly encountered during the winemaking process. The first section is a description of the types of stress to which wine yeast strains are exposed during their life cycle, and in particular during grape must fermentation. In a second section, the molecular mechanisms involved in perceiving environmental changes and responsible for implementing the specific cellular adaptation to the changed conditions are discussed. The conclusion highlights how the data presented in this review can lead to scientifically sound strategies for the improvement of wine yeast strains.

\section{THE LIFE CYCLE OF A WINE YEAST STRAIN - A STRESS- FUL JOURNEY}

To ensure rapid and complete grape must fermentation, and to achieve a degree of reproducibility in the character of specific wines, most fermentations are conducted with selected, industrially produced wine yeast strains that are inoculated into the must after pressing. Inoculated fermentation is differentiated from socalled natural, spontaneous fermentation, which is carried out by yeast strains naturally present on the grapes or the winery equipment. During both inoculated and spontaneous fermentation, a number of different non-Saccharomyces species, also referred to as "wild yeast", play an important role in the initial phases of the process (Boulton et al., 1995; Fugelsang, 1997). The most important of these wild yeast are from the genera Brettanomyces, Candida, Debaryomyces, Hanseniaspora, Kloeckera, Kluyveromyces, Metschnikowia, Pichia, Schizosaccharomyces, Torulaspora and Zygosaccharomyces (Pretorius et al., 1999; Khan et al., 2000; Pretorius, 2000; Van der Westhuizen et al., $2000 \mathrm{a}, \mathrm{b})$. Interestingly, these studies show that $S$. cerevisiae is found in very small numbers in vineyards and on grapes, and the debate on the real "natural habitat" of this yeast is still not closed. 
The low numbers could suggest that the true ecological niche of $S$. cerevisiae in a natural environment is still to be identified (Pretorius et al., 1999).

It is therefore not surprising that the initial stages of a spontaneous fermentation are usually dominated by the yeast species found in the highest numbers in the vineyard and on grape skins. Only once ethanol has reached concentrations which inhibit the growth of these yeast is $S$. cerevisiae able to out-compete these species and complete the fermentation (Boulton et al., 1995). This fact highlights one of the stress-related specific adaptations of $S$. cerevisiae strains during the winemaking process, the increasing tolerance to high ethanol concentration.

On the other hand, industrial wine yeast strains have been produced for optimal fermentation ability and behaviour in wine must, and the high number of cells inoculated at the beginning of fermentation, usually around $10^{6}-10^{7}$ cells per ml of must, in most cases ensures that this yeast will dominate the fermentation from beginning to end (Delteil \& Aizac, 1989; Petering et al., 1991; Fugelsang, 1997). The conditions encountered by the yeast during wine fermentation are listed in Table 1.

There is, however, a second set of criteria to which industrial yeast must respond. The manufacturing process of yeast strains itself requires some specific adaptations, in particular the ability to efficiently produce biomass in aerobic conditions and to survive long periods of storage, either dried or frozen. The conditions prevailing during the production process are also shown in Table 1. An efficient industrial yeast will have to be able to adapt to all the conditions listed. The table clearly shows that the con-

\section{TABLE 1}

Comparison of growth conditions during wine fermentation and industrial production process.

\begin{tabular}{ll}
\hline Wine fermentation & Industrial production
\end{tabular}

\section{Chemical parameters}

High sugar $(200 \mathrm{~g} / \mathrm{l})$

Several essential nutrients potentially limiting

Low to very low oxygen concentration

Presence of $\mathrm{SO}_{2}$

High ethanol

High levels of $\mathrm{CO}_{2}$

Potential presence of toxic metals (copper)

Highly variable supply of nitrogen sources

\section{Biological parameters}

Presence of competing microorganisms

Potential presence of toxins (mycotoxins or bacterial toxins)

Xenobiotics

\section{Physical parameters}

High density environment (hyperosmotic pressure)

Temperature changing, but mostly below optimal

Low pH (3-3.7)

Not encountered

Not encountered

Growth conditions permanently changing with advancing fermentation (availability of nutrients, ethanol, $\mathrm{CO}_{2}$ )

\section{Yeast metabolic activity}

Efficient fermentative metabolism

Efficient growth in suboptimal conditions

\section{Wanted end products}

High ethanol

Low biomass
Low sugar $(<1 \mathrm{~g} / 1$ in fed-batch)

Supplemented for all potentially limiting nutrients

High oxygenation rate

$\mathrm{No} \mathrm{SO}_{2}$

No or very low ethanol

Very low $\mathrm{CO}_{2}$

Absence of toxic metals

Constant supply

Sterile environment

Absence of toxins

Absence of xenobiotics

Low density environment

Temperature adjusted for efficient growth

Optimal pH (around 5)

Desiccation

Freezing-thawing

Growth conditions maintained constant

Efficient respiratory metabolism

Efficient growth in optimal conditions

High biomass 
ditions encountered during the two processes differ fundamentally: low sugar and high oxygen during yeast production $v s$. high sugar and low oxygen during wine fermentation. However, the table also shows a common denominator that can be used to describe most of the requirements that the yeast must fulfill in both conditions: stress resistance.

The following section describes the conditions and stress factors encountered by an industrial $S$. cerevisiae wine yeast strain during its life cycle; first during production and maintenance, then during wine fermentation. We have not considered stresses that might be specifically encountered by $S$. cerevisiae strains that are found during spontaneous fermentation, since little is known about their natural habitat and therefore about the specific stress conditions that might be associated with this habitat. In any case, these stresses will not be of a fundamentally different nature from the ones encountered by industrial yeast.

\section{Stresses during wine yeast production and maintenance}

To be kept alive over long periods between production runs, a typical industrial wine yeast strain is stored frozen at $-80^{\circ} \mathrm{C}$ as a stock sample. This is necessary to guarantee that the cells inoculated into a starter culture before large scale production are identical to all the previous batches of the same strain. Maintaining a strain in conditions appropriate for growth can lead to the slow accumulation of mutations, the so-called genetic drift (Mortimer et al., 1994; Pretorius, 2000), potentially resulting in the modification of some of the characteristics for which the strain was initially selected. Inoculation from the same frozen stock therefore ensures that the same strain is produced time and time again. Freezing, however, is an extreme stress condition, and several yeast strains are unable to sustain the process, making them unsuitable for industrial production (Park et al., 1997). Yeast normally respond to a sudden decrease in temperature (cold shock) by accumulating trehalose, which has a protective effect and increases cryoresistance (Kim et al., 1996; Van Dijck et al., 1995; Diniz-Mendes et al., 1999), and by inducing a specific set of genes (Kondo \& Inouye, 1991; Tanghe et al., 2000).

To improve the survival rate during storage, the cells are frozen in a solution with high glycerol content, usually between 15 and $40 \%$. Glycerol is naturally synthesised by yeast and other organisms as a by-product of the glycolytic pathway, and fulfills a major stress-protection role as an osmoprotectant compatible solute during hyperosmotic shock (see section on osmotic stress later in this review) and acts as a freeze protectant (Hohmann, 1997; Scanes et al., 1998). Even when glycerol is added to the freeze culture, the viability of yeast after long term storage at $-80^{\circ} \mathrm{C}$ varies according to the strain and the conditions prevailing during the freezing process, in particular the growth phase. As for all stress conditions, cells that have entered stationary phase after nutrient deprivation are more resistant than exponentially growing cells (Fuge \& Werner-Washburn, 1997; Park et al., 1997), which may be explained at least in part by the high trehalose content of stationary phase cells. After thawing, the strains are plated onto a rich growth medium, and grown under optimal growth conditions at $30^{\circ} \mathrm{C}$. During this time of fast growth, stress resistance is low, and even mild shocks can have major consequences on growth speed and viability. The inverse correlation between growth and proliferation on the one hand and stress-resistance on the other is one of the recurrent themes of research into stress resistance (Fuge \& Werner-Washburn, 1997; Mager \& Hohmann, 1997; Thevelein \& De Winde, 1999).

After verification of the absence of contamination and the positive identification of the strain (karyotyping), the cells are inoculated into a preculture of a small volume, typically $250 \mathrm{ml}$, from which they are reinoculated after 24 to 48 hours into a large batch fermentation tank. While media composition throughout this process always favours optimal growth, each inoculation into a new medium exposes the strain to a number of stress conditions: a new culture medium results in a change in osmotic pressure, perhaps a change in temperature and also in a new nutrient balance. These stresses are usually considered mild, but will nevertheless require a period of adaptation. The time required for this adaptation results in the so-called lag-phase, characterised by the absence of cellular growth. The lag-phase, which is typical for all newly inoculated cultures, is therefore another manifestation of a stress-induced adaptation period. Industrial yeast strains in general should be able to adapt quickly to new media and growth conditions to accelerate the production process.

The production process itself finally takes place in large fermentation tanks using so-called fed-batch conditions. These conditions are optimised for the production of biomass, or, to put it differently, for the optimal conversion of the energy contained in nutrients into yeast growth, and are similar to the methods used for baker's yeast production. In a typical fed-batch culture, the medium contains abundant nutrients but low concentration of glucose, which is continuously added to the growth media, usually in the form of diluted molasses (Kraus et al., 1983, 1984). At the same time, oxygen concentrations are kept high, resulting in respiratory metabolism with high biomass formation and low or no ethanol production. The high oxygen levels also result in the production of unsaturated fatty acids, an important factor for efficient fermentation because of their effect on ethanol tolerance (Boulton et al., 1995). The stress resistance of yeast cells during this production phase is low, again highlighting the inverse correlation between stress-resistance and growth and proliferation.

Toward the end of the yeast manufacturing process when the biomass has reached the desired level, the yeast is briefly deprived of oxygen and carbon source to induce some of the stress response mechanisms which will result in particular in an increase in the cellular trehalose content and the accumulation of stress protection proteins. This step is of particular importance, since the induced stress responses will protect the cells during the particularly stressful subsequent steps in the production process and guarantee their survival. Following the production run, the yeast is concentrated through centrifugation, then washed and dried to be sold as active dried yeast. Both washing and drying create intense stresses, which require the protective presence of trehalose, stress-related proteins and specific membrane constituents (Van Dijck et al., 1995; Sales et al., 2000). Washing with water results in a hypoosmotic stress, creating high turgor pressure within the cell because of water influx and necessitating the quick release of compatible solutes (Hohmann, 1997). Yeast strains also show highly variable sensitivity to desiccation, and some data indicate that trehalose may play a role in protecting cells against the effects of the drying process (Eleutherio et al., 1995). Other researchers, however, have found no direct correlation between trehalose content and desiccation resistance 
(Krallish et al., 1997). In any case, a high survival rate is of crucial importance at this stage, since a high viable cell count is the most important parameter when inoculating a $S$. cerevisiae strain into the must. A significant drop in survival rates during desiccation and rehydration could therefore have disastrous consequences for the winemaking process.

After desiccation, the yeast is vacuum packed under nitrogen and sold as active dried yeast to winemakers. In this dried state, yeast cells will stay viable for extended periods in the absence of all metabolic activity.

\section{Stresses during wine fermentation}

Rehydration and inoculation - osmotic stress and some other minor problems: Both rehydration and inoculation result in several stresses, the most significant of which is probably a hyperosmotic shock experienced during inoculation.

The yeast sold as active dried yeast is not directly inoculated into the must, but is first added to a small volume of warm (35$40^{\circ} \mathrm{C}$ ) water. This rehydration process is required to reestablish functional membranes and metabolic activity, since water activity in the dried yeast is too low to maintain any of these processes (Boulton et al., 1995). Little data are available regarding stress-related responses during the period of rehydration, but common sense would suggest that several types of stress will be experienced by the yeast. These should probably include heat stress and hypoosmotic shock when inoculated into warm water. The situation is difficult to analyse, since the cells emerge from a metabolically inactive state and may not be able to properly perceive and respond to stress conditions. In addition, no detailed studies have been carried out to analyse the cellular response during this process, but it has been shown that survival depends on the physiological condition of the cells before the beginning of the drying process (Eleutherio et al., 1995; Krallish et al., 1997) and on the temperature and the kinetics of rehydration (Poirier et $a l ., 1999)$. This again emphasises the importance of the induction of stress response mechanisms at the end of the production run, which will largely determine the ability of the yeast to withstand these challenges.

The inoculation into the must presents the yeast with a number of new challenges. Grape must presents far from optimal growth conditions for any organism. The must is a high density substrate, and contains a high concentration of osmotically active substances, in particular glucose and fructose. After inoculation, the yeast experiences hypertonic conditions, which leads to an efflux of water from the cell, diminished turgor pressure, and reduced water availability. Yeast cells respond to such a hyperosmotic shock through a number of mechanisms, including the modification of the cell wall and the cytoskeleton (Slaninova et al., 2000), and the synthesis of a compatible compound, glycerol, to reestablish an osmotic equilibrium (Hohmann, 1997; Scanes et al., 1998). A compatible compound is defined as an osmolyte that does not negatively affect the cellular metabolism or structure and can be accumulated at high concentration. Different organisms use different compatible compounds, including potassium ions, amino acids like proline, sugars and alcohols (Hohmann, 1997), as well as different strategies of compound accumulation. Accumulation can occur either through active uptake from the environment or through biosynthesis. In S. cerevisiae, glycerol appears to be the sole compatible osmolyte accumulated in response to osmotic stress, and is produced through biosynthesis (Hohmann, 1997; Scanes et al., 1998). This synthesis is regulated by the high osmolarity glycerol (HOG) signal transduction pathway (Albertyn et al., 1994), a mechanism that is reviewed in more detail later.

Fermentation-induced stress conditions: When the cell has adapted to the new environment, grape juice, fermentation begins. The biological activity of the yeast during fermentation leads to a number of stress conditions, some mild, some potentially severe. The most important factors are nutrient limitation and starvation, ethanol toxicity and temperature variations.

Nutrient limitation and depletion: During wine fermentation, several types of nutrients may become limited or exhausted at different stages of the fermentation, which leads to reductions in growth rate and fermentation efficiency or even a complete arrest of fermentation. Nutrient limitation and starvation are stressinducing phenomena and result in a number of stress-associated responses, including the synthesis of trehalose and the induction of heat shock proteins (De Winde \& Thevelein, 1997). At inoculation, the initial nutrient content of an average grape must meets most or all of the theoretical requirements of $S$. cerevisiae. Several nutrient availability-related problems nevertheless can occur while fermentation progresses.

First, both the nutritional requirements of $S$. cerevisiae and the composition of grape must are highly variable, and each fermentation will follow a different path. The nutritional requirements of S. cerevisiae are strain and growth condition dependent, and each fermentation presents a slightly different nutrient-utilisation pattern. In addition to intrinsic differences among yeast strains, growth condition dependent variables include the presence of other organisms in the must (which might consume some of the nutrients), as well as a wide range of enological practices which influence yeast growth. The nutritional content of grape must also varies widely and depends on factors such as the grape variety, the soil type, viticultural practices like soil fertilisation (particularly with nitrogen compounds) and the maturity of the grapes at harvest. As a consequence of the variability of these parameters, the requirements of specific yeast strains may not be met by the nutritional composition of a specific must (Fleet, 1993; Boulton et al., 1995; Fugelsang, 1997).

Second, during the course of fermentation, an imbalance can occur between the quantity of hexoses (glucose and fructose) that must be fermented to achieve dryness and the assimilable nitrogen. The reasons for this imbalance are not related to the total amount of theoretically available nitrogen in the must, but is rather a consequence of the inability of $S$. cerevisiae to assimilate all of these sources efficiently. The major nitrogen compounds in grape must include several free amino acids, particularly (in order of decreasing concentration in an average grape must) proline, arginine, alanine, glutamate, glutamine, serine and threonine, as well as ammonium ions and $\gamma$-aminobutyrate (Boulton et al., 1995). The concentration of most of these compounds varies significantly according to the grape variety and other parameters. S. cerevisiae, however, cannot use all of these compounds with similar efficiency (Cooper, 1982a, b). While ammonium and some amino acids like glutamate are favourite sources of metabolisable nitrogen, other amino acids can only be used inef- 
ficiently (e.g., proline), or not at all (e.g., lysine). A further complicating factor is that amino acids can either be used directly, i.e. as such, for macromolecular biosynthesis, or be enzymatically modified. In the second case, they can either be transformed into a related compound or be catabolised in order to release ammonium ions and bound nitrogen for general biosynthetic purposes (Cooper, 1982a, b; Boulton et al., 1995).

The utilisation of nitrogen-containing compounds by $S$. cerevisiae follows a complex, relatively well-established pattern during wine fermentation (Boulton et al., 1995). In a first phase after inoculation, the yeast takes up all the nitrogenous compounds that can be used directly as building blocks for the biosynthesis of macromolecules. This leads to a rapid depletion of those amino acids that are present in low concentrations. In order for yeast cells to grow, these amino acids must then be neo-synthesised from precursor molecules, requiring the uptake of compounds that can serve as a general source of metabolically usable nitrogen. In controlled laboratory conditions, a specific order of preference has been established for those compounds (Cooper, 1982a, b). Favourite sources, corresponding to those compounds that are efficiently metabolised, include aspartate, glutamate, glutamine and ammonium ions, and are taken up preferentially, while their presence in the media represses the uptake of other, less efficient nitrogen sources, an effect known as $\underline{n}$ itrogen $\underline{c}$ atabolite $\underline{r}$ epression (NCR). Once these sources have been depleted, other nitrogen compounds like proline and other amino acids will be utilised (Cooper, 1982a). Studies on nitrogen uptake and utilisation in grape must show a more complex, sometimes contradictory picture (Monteiro \& Bisson, 1991a, b; 1992a, b; Ough et al. 1991), since most amino acids, and particularly those present in limited amounts, appear to be taken up rapidly before growth begins. Some of the factors responsible for the difficulties in correlating data from laboratory experiments with those observed in grape must include (i) the variability of nitrogen sources in grape must; (ii) the ability of yeast to store significant amounts of nitrogen, particularly amino acids, in the vacuole; (iii) the difficulty experienced by $S$. cerevisiae cells to transport amino acids when ethanol levels reach a threshold (around 4\% v/v); and (iv) the absence of oxygen, which precludes the utilisation of proline. The reasons for the effect of ethanol on amino acid uptake is discussed in the section dealing with ethanol-related stresses.

The data presented above indicate that $S$. cerevisiae cells may have to switch their nitrogen source several times during a single fermentation. The switching from a preferred compound to a less preferred compound is experienced as a mild stress by the yeast cells, and, in laboratory conditions, results in a transient reduction in growth rate. Nitrogen starvation, on the other hand, only becomes a problem in later stages of the fermentation process, and is in most cases due to the inhibition of uptake by ethanol (Boulton et al., 1995).

A third nutrient-related problem of wine fermentation is the near absence of oxygen. Oxygen is required as a structural component in numerous organic molecules, and fermentation is impossible in the complete absence of molecular oxygen (Visser et al., 1990; Ribéreau-Gayon et al., 1972). Efficient growth, even under fermentative conditions where the organism does not rely on oxygen for energy production, requires a significant amount of free oxygen, and the addition of oxygen during specific phases of the fermentation was shown to have beneficial effects on fermentation kinetics (Fleet, 1993; Ribéreau-Gayon et al., 2000). The oxygen requirement is further increased by the high levels of ethanol accumulating during fermentation. Ethanol resistance indeed requires membranes containing high percentages of unsaturated fatty acids and ergosterol, synthesis of which relies on the availability of oxygen (Alexandre et al., 1994). Problems due to other limiting nutrients in wine fermentation have been described and include, for example, phosphate limitation (Boulton et al., 1995).

During wine fermentation, the yeast is therefore potentially exposed to several nutrient-related stress conditions. In some cases, as in nitrogen, the problem does in most cases not reside in the absence of nitrogen-containing compounds, but either in the necessity to switch from a favourite source to a less favourite one, or in the inability to take up nitrogen-containing compounds from the must because of the high ethanol content. In other cases, for example phosphate, the problem is the complete absence of an essential compound. In all cases, the switching from one source to another, as well as the disappearance of essential compounds, results in stress-related adaptation leading to reduced fermentation efficiency.

Ethanol toxicity: While fermentation proceeds and nutrients are depleted, ethanol accumulates. Ethanol is toxic to most organisms at relatively low concentrations, sometimes as low as $2 \%(\mathrm{v} / \mathrm{v})$, which gives an indication of its ability to efficiently disrupt biological processes and of the necessity of protective mechanisms to sustain high ethanol concentrations. The inhibitory effect of ethanol on specific growth rates of $S$. cerevisiae is well established, and has been modeled mathematically (Beavan et al., 1982; Pamment, 1989). The biological effect of ethanol on cellular growth rates and fermentation efficiency is largely a result of changes in the properties of cellular membranes, in particular an increase in membrane permeability and changes in membrane fluidity (Alexandre et al., 1994; Sales et al., 2000). The increased permeability has numerous physiological consequences, not least of which is the dissipation of the proton motor force which allows the active transport of numerous compounds, in particular amino acids, through proton symport. The cell maintains the intracellular $\mathrm{pH}$ through the stress-regulated enzyme $\mathrm{H}^{+}$-ATPase, which pumps $\mathrm{H}^{+}$ions out of the cytoplasm into the surrounding substrate in an energy (ATP) dependent mechanism (Serrano, 1993; Braley \& Piper, 1997; Ambesi et al., 2000). The ion gradient created by this mechanism is used by numerous transport systems, which use the electrochemical energy created by the gradient to actively transport substances against their concentration gradient into the cell by cotransporting a proton together with the specific metabolite (proton symport). Increased permeability of the membrane to $\mathrm{H}^{+}$results in intracellular acidification, particularly in the case of a substrate with a low $\mathrm{pH}$, as is the case with grape must (Boulton et al., 1995). In addition, ethanol appears to have an inhibiting effect on $\mathrm{H}^{+}$-ATPase specific activity, contributing to the dissipation of the proton motor force. As a consequence, both the intracellular metabolic activity and the proton gradient dependent transport processes are reduced (Alexandre et al., 1994).

Ethanol has numerous broad additional effects on cell physiology, and appears to affect most cellular processes. This general 
effect has been related to reduced water activity, a measure of water availability. All biological processes are dependent on the presence of water, and reduced water availability affects all compartments of the cell. Affected processes include enzymatic activities, protein folding and membrane structure (Hallsworth, 1998). The cellular response to high ethanol content is strikingly similar to the heat stress dependent response, and both responses may be designed to reduce the effects of water stress (Piper, 1995; Hallsworth, 1998). As in the case of other stresses, the cellular response includes the synthesis of trehalose and the induction of stress protection or heat shock proteins (Piper, 1997). In addition, the membrane composition is changed fundamentally, with increases in the percentage of unsaturated fatty acids and changes in sterol content (Arneborg et al., 1995).

Temperature: During fermentation the cells release a significant amount of energy in the form of heat, and every change in temperature is perceived as a stress by the cell (Piper, 1997). Wine yeast are particularly sensitive to changes in temperature because of the suboptimal composition of the growth substrate, particularly in the latter stages of fermentation, when ethanol levels are high. The effects of ethanol and high temperature stresses are very similar and mutually amplify cellular sensitivity (Piper, 1995). Today, most wine fermentations are conducted under temperature-controlled conditions, with white wine fermentation being conducted at cooler temperatures $\left(10-15^{\circ} \mathrm{C}\right)$, and red wine fermentation at higher temperatures $\left(18-25^{\circ} \mathrm{C}\right)$. However, increases in temperature of as little as $2-3^{\circ} \mathrm{C}$ have been shown to have a negative influence on fermentation efficiency (Henschke, 1998), and such small variations cannot always be avoided in the large fermentation tanks that are used in the industry. Thus, heat stress can still have significant consequences, even in a temperature-controlled fermentation.

Other stress factors during fermentation: Several other factors are perceived as stresses by $S$. cerevisiae during some wine fermentations. These include the presence of high levels of $\mathrm{SO}_{2}$, particularly at the beginning of the fermentation process, and of high levels of $\mathrm{CO}_{2}$, particularly in sparkling wine fermentation. The presence of competing microorganisms as well as of toxins, either mycotoxins or bacterial toxins, that might be produced by these organisms, constitutes another potential challenge. These stresses, however, are not inherently part of alcoholic fermentation, but rather depend on winemaking practices and cellar operations, or are only encountered in some specific winemaking conditions (sparkling wine). Considering the incredibly large amount of data that has accumulated over the last years with regard to stress-response mechanisms, their inclusion would expand this review beyond reasonable length. The following section therefore focuses on some selected and relatively well-established aspects of the molecular mechanisms required to protect $S$. cerevisiae against the deleterious effects of those stress conditions that are an inherent part of wine fermentations. They include the response to temperature stress, osmotic shock, nutrient availability and ethanol toxicity.

\section{MOLECULAR AND CELLULAR RESPONSES TO STRESS CONDITIONS}

\section{A short introduction to the molecular aspects of stress response mechanisms in $S$. cerevisiae}

The first molecular stress response to be studied in some detail, not only in $S$. cerevisiae but in a large number of organisms, was the induction of so-called $\underline{h}$ eat-shock protein $\underline{s}$ (Hsps), a set of proteins whose synthesis is strongly increased when organisms are exposed to sudden increases in temperature (Mager \& De Kruijff, 1995; Piper, 1997; Morano et al., 1998). This research showed that several families of Hsps are well-conserved throughout evolution, displaying a high degree of sequence conservation in all organisms, from bacteria to higher eukaryotes, and suggesting a central role in cellular metabolism for these proteins. For example, the Hsp70p (DnaK) protein of Escherichia coli shows about $50 \%$ amino acid sequence identity with human Hsp70p (Lindquist \& Craig, 1988).

Most Hsps are induced in response to a number of or all investigated stress conditions, suggesting that Hsps can be classified as general stress-protection proteins (Ruis \& Schüller, 1995; Piper, 1997). However, the data show that this "general" response is complemented by molecular adaptations which are specific to each type of stress (Mager \& De Kruijff, 1995; Ruis \& Schüller, 1995). Specific induction patterns are observed for all stressresponse mechanisms, including for example heat stress, hyperosmotic and hypoosmotic stress, and nutrient limitation. A number of these specific adaptations were studied extensively, and include the synthesis of glycerol in response to hyperosmotic stress, the synthesis of storage carbohydrates like glycogen in the case of nutritional (especially carbon-source) deprivation, or the synthesis of trehalose in response to a number of stresses.

These molecular mechanisms, induction of Hsps, glycerol and glycogen synthesis, all correspond to the final implementation of general or specific stress protection programmes. Before these molecular programmes can be implemented by an organism or a cell, the stress condition itself must first be perceived, and the information must be transmitted to the relevant genes and enzymes responsible for the implementation. More recently, the focus of research has shifted to the study of the mechanisms allowing the perception of environmental changes and to the molecular pathways required to transmit the perceived signal to the relevant compartments of the cell, a process referred to as "signal transduction".

This research has yielded a large amount of data suggesting the existence of a complex network of signal transduction pathways which rely on a limited number of signal transduction modules. These modules include stress signal receptors, receptor-associated GTP-binding proteins (G-proteins), and intermediate modules consisting mainly of a large number of kinases, which are either regulated by small molecules called second messengers like cyclic AMP (cAMP) or arrayed in cascades which are referred to as $\underline{\text { mitogen }} \underline{a}$ ctivated protein $\underline{k}$ inase (MAPK) cascades. In this model, the last kinase in a signaling pathway phosphorylates specific target proteins, which may include transcription factors, metabolic enzymes and structural proteins of the cytoskeleton. Phosphorylation modulates the activity of these proteins, either inducing or suppressing their activity. As a consequence, tran- 
scription factors transcribe - or stop to transcribe - their specific target genes, and the cellular structure and metabolism adjust to the changed environmental conditions. A schematic representation of a general model of a stress condition induced signal transduction cascade is represented in Fig. 1.

The heat shock proteins: general protection and recovery from stress-induced structural damage

The existence of a "general" stress response was suggested by data showing that the exposure of an organism to a specific stress condition subsequently results in increased stress resistance not only to the specific stress experienced, but to a number of other stress conditions. This phenomenon of cross protection or cross resistance was also demonstrated in $S$. cerevisiae, where exposure to a mild heat stress not only increases resistance and survival to more severe heat exposure, but also increases protection against osmotic or oxidative stress (Mager \& De Kruijff, 1995; Ruis \& Schüller, 1995). Several families of Hsps are induced in most, if not all, stress conditions, and are therefore considered to be part of this general stress response. Stress conditions which induce

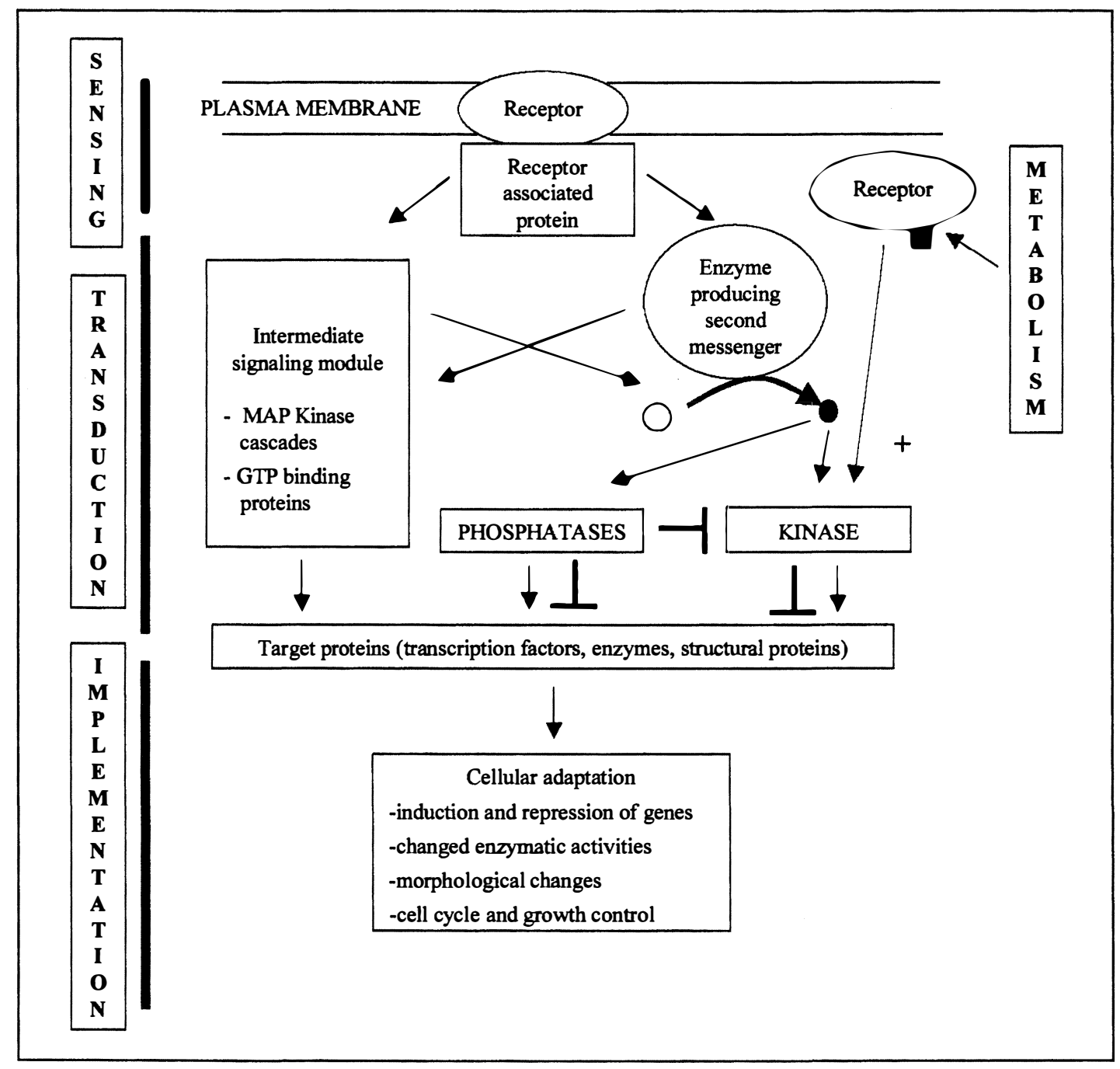

FIGURE 1

Schematic representation of a signal transduction cascade. The elements represented are found in all eukaryotic organisms and are almost exclusively associated with signal sensing and information transduction events. The $S$. cerevisiae genome encodes numerous receptors which sense specific compounds, two heterotrimeric and numerous small G-proteins, which are activated when bound to GTP, and five different MAP kinase cascades. Numerous other kinases exist outside of the structure of MAP kinase cascades and regulate all aspects of cellular metabolism. Second messengers include cAMP, calcium ions, and other small compounds. The final element of most cascades are kinases which regulate specific target proteins through phosphorylation, and are themselves regulated by phosphatases. Both kinase and phosphatases can have an activating or inhibiting effect on their target. Targets are frequently transcription factors which regulate entire sets of genes. Not all sensing occurs at the level of the membrane; intracellular metabolites can also be sensed and activate specific pathways. 
sets of Hsps include the disappearance of nutrients from the growth substrate, the shift from a favourite source of a specific nutrient to a less favourite source, changes in temperature, $\mathrm{pH}$, osmotic pressure, and the presence of high ethanol concentrations, toxic substances and reactive oxygen species like $\mathrm{H}_{2} \mathrm{O}_{2}$ (De Winde \& Thevelein, 1997; Mager \& Hohmann, 1997; Piper, 1997). In general, the more favourable the growth conditions, the faster the growth speed, the lower the concentration of Hsp proteins within a cell, and the lower the cell's intrinsic stress resistance. These correlations suggest a direct connection between stress and growth control as well as an important role for Hsps in stress protection.

Hsp families are grouped according to sequence homologies and are named according to the average apparent molecular weight of their members. In S. cerevisiae, Hsps and Hsp families include Hsp104p (member of the Hsp100p family), Hsp83p (member of the Hsp90p family), Hsp70p, of which there are at least 10 members in $S$. cerevisiae, Hsp60p and several small Hsps, including Hsp30p, Hsp26p and Hsp12p (Mager \& De Kruijff, 1995; Piper et al., 1997; Morano et al., 1998). Several genes displaying extensive sequence homologies with stress-induced Hsps are also found within the yeast genome, but are not induced upon stress. These genes frequently are constitutively expressed or may, in some cases, be regulated in response to other factors. The existence of these homologous genes indicates that some of the molecular functions of Hsps are required during normal growth. The expression levels and the degree of responsiveness to stress conditions of different $H S P$ genes also vary within and among Hsp families (Piper et al., 1994; Piper, 1997; Morano et al., 1998).

Role of Hsp in cellular metabolism: For a relatively long period in the 1980's, little data were available regarding the role of Hsps in cellular metabolism. Lewis \& Pelham (1985) first suggested that Hsp70p might interact with denatured proteins to assist protein solubilisation, folding or repair in an ATP-dependent manner. Since then, numerous studies have confirmed that most stressinduced Hsps are indeed involved in the protection, rescue, solubilisation and repair of denatured and aggregated proteins (Piper, 1997; Morano et al., 1998). On the other hand, the main role of the constitutively expressed or only weakly induced members of Hsp families appears to be maintaining the non-folded state of newly synthesised proteins for incorporation into protein complexes or in creating a translocation-competent conformation for transfer from the cytoplasm into another cellular compartment (Jensen \& Johnson, 1999). All these functions, broadly described as chaperone activity, were confirmed for a number of proteins, including Hsp40p, Hsp70p, Hsp90p, and Hsp104p (Piper, 1997; Morano et al., 1998).

Examples of the wide range of specific activities of Hsps and Hsp homologs include:

(i) the maintenance of proteins in a non-folded or conformational immature state by members of the Hsp70p family to facilitate their translocation across the membranes of the endoplasmic reticulum and the mitochondria (Chirico et al., 1988; Deshaies et al., 1988; Jensen \& Johnson, 1999);

(ii) the role of mitochondrial Hsp70p, encoded by the gene $S S C 2$, in the maturation of the mitochondrial protein Yfh $1 \mathrm{p}$
(Knight et al., 1998);

(iii)the control of signal transduction pathways by Hsps; Ssa1p, a Hsp70p homologue, regulates the cAMP-dependent signal transduction pathway by associating with and downregulating Cdc25p, one of the regulatory proteins of this pathway (Geymonat et al., 1998);

(iv)the rescue of previously aggregated and denatured cytoplasmic proteins by a complex including Hsp104p, Hsp70p and Hsp40p (Glover \& Lindquist, 1998);

(v) the repair by Hsp104p and Hsp70p of proteins in the endoplasmic reticulum denatured by excessive heat (Hänninen et al., 1999);

(vi)the association between members of the Hsp70p family with ubiquitine-like proteins which direct denatured proteins to the ubiquitine-dependent protein degradation pathway (Kaye et al., 2000). Some polyubiquitine genes like UBI4 are themselves regulated in a stress-dependent manner (Simon et al., 1999);

(vii) the acceleration of the reactivation of heat-damaged proteins by Hsp90p (Nathan et al., 1997).

A surprising aspect of the early studies of Hsp function is that while the chaperone activity of Hsps was unraveled, little data indicated that specific Hsp proteins had an effect on stress resistance. Indeed, gene disruption experiments in $S$. cerevisiae indicated that most $H S P$ genes could be deleted without changing the ability of cells to respond to and survive stress conditions, challenging the generally accepted theory that these proteins would protect cells against stress (Lindquist \& Craig, 1988; Praekelt \& Meacock, 1990). However, Sanchez \& Lindquist (1990) showed that Hsp104p has a direct role in heat-stress protection. Cells of a strain deleted for HSP104 no longer acquire increased thermotolerance when pre-exposed to a mild heat-shock treatment. The same research group also showed that Hsp104p is required for tolerance to several other forms of stress, including high ethanol concentration, sodium arsenite and long-term storage in the cold (Sanchez et al., 1992). Interestingly, it appears that Hsp104p is sufficient for the acquisition of thermotolerance by $S$. cerevisiae, since high expression levels of the protein can protect the cells from thermal shock in the absence of a pretreatment, i.e. in the absence of any other inducible factor (Lindquist \& Kim, 1996).

Similar to other heat-induced Hsps, the molecular function of Hsp104p is to promote the resolubilisation and reactivation of heat-damaged proteins. For example, Hsp104p contributes to the resolubilisation of heat-inactivated luciferase, a heterologous protein expressed in $S$. cerevisiae for experimental purposes, from insoluble aggregates (Parsell et al., 1994) and, together with Hsp70p and Hsp40p, it was shown to directly reactivate denatured and aggregated proteins (Glover \& Lindquist, 1998). As with all Hsps, the protein sequence and function is evolutionarily well conserved, and soybean Hsp101p, the plant equivalent to yeast Hsp104p, was shown to restore acquired thermotolerance to a S. cerevisiae strain deleted for the native HSP104 gene (Lee et al., 1994).

Other Hsps are also required for the survival of temperature shocks. For example, the mitochondrial member of the Hsp70p family, Ssc1p, is required for recovery from severe heat stress at $52^{\circ} \mathrm{C}$ (Nwaka et al., 1996). Morano et al. (1999) demonstrated 
that several elements of the Hsp90p complex, in particular Hsp82p, are able to efficiently suppress temperature sensitivity of a heat shock transcription factor (Hsflp) mutant deleted for its $C$ terminal region. The mutated factor is unable to induce $H S P$ genes in response to heat stress, and the data therefore suggest that the Hsp90p chaperone complex is essential for heat protection in the absence of other heat activated proteins.

The transcriptional control of HSP and other stress induced genes: Despite the considerable amount of data that has been published over the last decades on HSP genes and other genes that are induced during stress conditions, the full picture of their regulation has yet to be completed. Fig. 2 summarises the relation between some of the major environmental stresses and specific transcription factors which are discussed in more detail in the following section.

The heat shock factor Hsfl: The first transcription factor specifically required for the activation of $H S P$ genes was isolated in S. cerevisiae by Sorger \& Pelham (1987), and the HSFl gene was cloned by Wiederrecht et al. (1988) and by Sorger \& Pelham (1988). The gene is essential and encodes a protein, Hsflp, of 833 amino acids. The protein binds as a homotrimer to a specific DNA sequence, the $\underline{h}$ eat-shock $\underline{e}$ lement (HSE), which is present in the promoter of most HSP genes (Sorger \& Nelson, 1989). Besides a DNA binding and trimerisation domain, Hsf1p has two transactivation domains, situated on both the $N$ - and $C$-terminal end of the peptide. Interestingly, the two domains appear to fulfill different functions; the $N$-terminal domain is responsible for constitutive activation of $H S P$ genes, while the $C$-terminal domain plays a significant role during heat stress induction (Nieto-Sotelo et al., 1990; Sorger, 1990). Accordingly, cells carrying a mutated version of the $H S F 1$ gene, encoding a Hsflp without a $C$-terminal domain, $\operatorname{Hsf}(1-583)$, are able to grow normally at 25 or $30^{\circ} \mathrm{C}$, but are unable to sustain severe heat stress or to grow at $37^{\circ} \mathrm{C}$. Hsflp is evolutionary well conserved and the genes encoding human or tomato Hsf are able to functionally substitute for the $S$. cerevisiae protein (Boscheinen et al., 1997; Liu et al. 1997). In higher eukaryotes, the control of binding of Hsf to its specific DNA sequence plays a major role in the transcriptional regulation of $H S P$ genes (Sorger et al., 1987). This control of the binding activity occurs largely via the regulation of the trimerisation of the factor, which is a prerequisite to DNA binding (Rabindran et al., 1993). In S. cerevisiae, on the other hand, Hsflp is permanently in a trimeric state and binds constitutively to the promoter of HSP genes (Jakobsen \& Pelham, 1988). The factor is required for the basal, constitutive expression of Hsps, which are necessary for normal cellular growth, while also maintaining a basal capacity to respond to minor stress conditions. Hsflp is also required for the heat stress-dependent induction of several, but not all of the genes encoding Hsps. However, it is still not fully understood how the heat-generated signal is transmitted to the transcription factor. Genetic evidence exists showing that both Hsp70p and Hsp90p associate with the factor and may negatively regulate its activity in the absence of stress (Boorstein \& Craig, 1990; Duina et al., 1998). Hsp90p has been shown to directly associate with Hsflp (Duina et al., 1998). In this case, the signal could be the accumulation of denatured or inadequately folded proteins, which would recruit the inhibiting Hsps and free

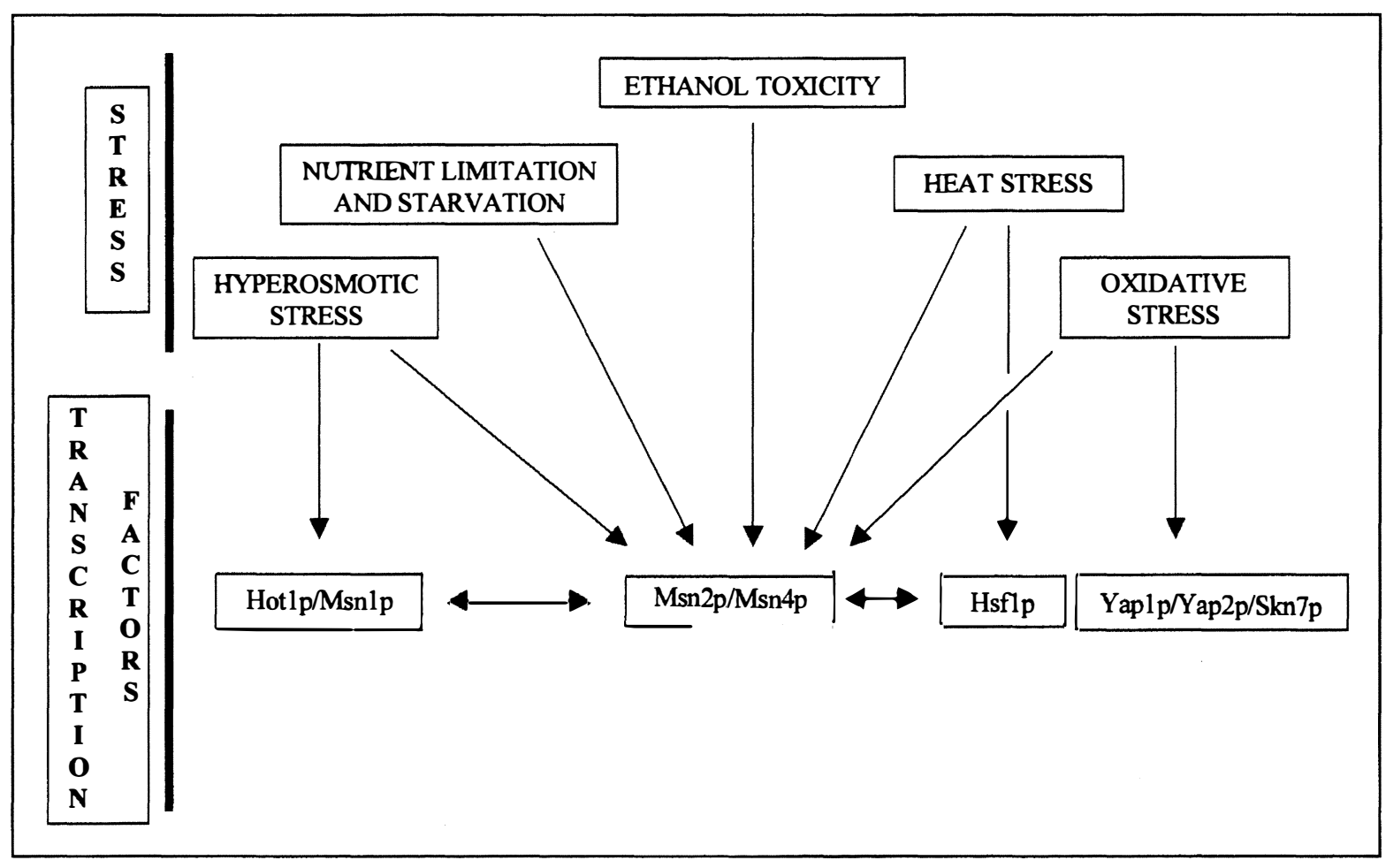

FIGURE 2

Representation of the best studied and most frequently encountered stress conditions and the most relevant transcription factors involved in the control of the expression of stress responsive genes in S. cerevisiae. 
the activating region of Hsflp. In addition, phosphorylation may play a role in activating the factor, since the protein is hyperphosphorylated after an increase in temperature (Sorger, 1990). It has also been suggested that Hsflp may be able to sense heat stress directly by undergoing conformational changes during increases in temperature. Recently, Hardy et al. (2000) presented evidence that small mutational changes which slightly alter Hsflp conformation can lead to significantly increased Hsflpdependent transcriptional activity, suggesting that this mechanism may play an important part in the induction of $H S P$ genes.

However, Hsflp is not the only factor involved in the induction of HSP genes. Current data suggest that the role of Hsflp is mainly to maintain basal transcription levels of those HSP genes that are required during normal cellular growth, while its role in stress dependent induction of a wide set of HSP genes seems to be limited to heat stress.

Msn2p/Msn4p, a transcription factor required for the induction of the multistress response: Since Hsflp appears to respond to heat stress, other factors must be responsible for the observed induction of Hsps to other types of environmental and metabolic stresses. Schmitt \& McEntee (1996) and Martinez-Pastor et al. (1996) presented evidence that a large proportion of the genes induced by stress conditions was regulated by the two zinc fingercontaining proteins Msn2p and Msn4p. The two proteins were shown to bind as a heterodimer to a specific nucleotide sequence (CCCCT) which had previously been identified as being required for stress-dependent activation of numerous genes, including the catalase-encoding CTT1 gene and the DNA damage-induced DDR2 gene (Kobayashi \& McEntee, 1990; Wieser et al., 1991). Kobayashi \& McEntee (1993) and Marchler et al. (1993) showed that the same sequence, named STRE for $\underline{s}$ tress $\underline{r}$ esponsive $\underline{e}$ lement, mediated induction of genes in response to several stress conditions, including temperature changes, osmotic variations and nutrient exhaustion. Functional STRE sequences were also identified in several $H S P$ gene promoters, including the promoters of HSP 104, HSP70 and HSP26, the promoters of trehalose synthesis genes, TPS1 and TPS2, and the neutral trehalase gene NTH1 (Winderickx et al., 1996; Moskvina et al., 1998; Thevelein \& De Winde, 1999; Zahringer et al., 2000).

Disruption of either MSN2 or MSN4 results in a significant reduction of the transcriptional activation of STRE-regulated genes, suggesting that the two proteins are required for most of the induction observed during stress responses. Data also indicate that Msn2p/Msn4p may play a central role in coordinating cellular growth and stress resistance. Several research groups have established a link between the activity of the cAMP-dependent kinase (PKA), thought to be a major component of growth-regulating mechanisms, and the general stress response regulated by Msn2p/Msn4p (Boy-Marcotte et al., 1998; Görner et al., 1998; Smith et al., 1998; Thevelein \& De Winde, 1999). The activity of Msn2p/Msn4p is repressed when PKA activity is high, and the intracellular localisation of Msn2p/Msn4p is strongly affected by PKA activity. During stress, Msn2p/Msn4p is translocated from the cytoplasm into the nucleus, and high PKA activity was shown to block this transfer and therefore the Msn2p/Msn4p-dependent induction of genes (Görner et al., 1998). Boy-Marcotte et al. (1998) showed that Msn2p/Msn4p are responsible for the induc- tion of numerous genes during the diauxic transition, when yeast cells adapt to growth on ethanol after having exhausted all the available fermentable carbon sources, and that the induced genes are all repressed by cyclic AMP.

While Msn2p and Msn4p appear to regulate the bulk of the STRE-dependent transcriptional activation occuring during stress responses, and are thought to be responsible for the cross-protective effect of stress-response mechanisms, a more complex picture has recently emerged. Disruption of MSN2 or MSN4 does not lead to the complete abolition of the stress response related induction of genes, indicating that other factors are contributing to the transcriptional control of STRE-regulated genes (Martinez-Pastor et al., 1996; Schmitt \& McEntee, 1996). The data suggest that Msn2p and Msn4p require specific combinations of transcription factors to regulate specific subsets of genes in response to specific stress conditions. In response to heat stress, Msn2p/Msn4p and the heat shock transcription factor Hsflp were shown to activate different subsets of HSP genes, and only a few genes appear to be regulated by both factors (Boy-Marcotte et al., 1999). Rep et al. $(1999,2000)$ showed that Msn2p and Msn4p require at least two additional transcriptional regulators, Hot $1 \mathrm{p}$ and Msn1p, to properly control the induction of genes during hyperosmotic stress. Each of these two factors, Hot1p and Msn1p, appears to favour a particular set of genes. During hyperosmotic stress, these factors regulate in particular the transcription of genes encoding proteins involved in glycerol biosynthesis, GPD1 and GPD2, to produce sufficient concentrations of this compatible solute to reduce the efflux of water and to reestablish sufficient turgor pressure (Hohmann, 1997; Scanes et al., 1998).

Other pathways regulating $H s p$ expression: Evidence is also mounting pointing to additional, as yet unknown, pathways which regulate specific $H S P$ genes and other stress-induced genes. Seymour \& Piper (1999) have shown that HSP30, a gene encoding a plasma membrane Hsp, is not regulated by either Hsf1p or Msn2p/Msn4p, while HSP12 was shown to be repressed by very low concentrations of glucose in a Msn2p/Msn4p-independent manner (De Groot et al., 2000).

Other stress responsive transcription factors acting independently of Msn2p/Msn4p: While STRE-dependent regulation plays a central role in most stress responses, other transcription factors appear to act independently of this system in some specific stress response mechanisms. The response to oxidative stress, for example, is regulated by several transcription factors, including Yap1p, Yap2p and Skn7p. Yap1p and Yap2p, which are members of the AP-1 family of eukaryotic transcription factors, were found to confer resistance to oxidative stress when overexpressed (Moradas-Ferreira et al., 1996), while disruption of the YAPl and $Y A P 2$ genes results in sensitivity to hydrogen peroxide and other oxidising agents (Stephen et al., 1995). Disruptions of SKN7, a gene which had been implicated in the regulation of both cellwall biosynthesis and the cell cycle (Brown et al., 1993; Morgan et al., 1995), also results in increased sensitivity to oxidative stress (Krems et al., 1996). Yap1p was shown to directly bind to a specific DNA sequence within the promoter of genes encoding products required for oxidative stress resistance. These include genes encoding thioredoxin (TRX2) (Kuge \& Jones, 1994) and thioredoxin reductase (TRRl) (Morgan et al., 1997), involved in the reduction of protein disulfides. They also include the genes 
encoding the enzymes required for glutathione metabolism, including glutamylcysteine synthetase ( $G S H 1)$, glutathione synthetase $(G S H 2)$ and glutathione reductase $(G L R I)$ (Sugiyama et al., 2000). In addition, Yap1p is also required for the induction of genes involved in the resistance to toxic compounds like cadmi$\mathrm{um}$, and induces genes specifically required for detoxification, for example the yeast cadmium-factor-encoding gene ( $Y C F 1)$, which specifies a glutathione $S$-conjugate pump (Wemmie et al., 1994). The induction of TRX2 and TRRI was shown to require a cooperation between $S k n 7 p$ and Yap1p, with both proteins binding directly to the promoter of TRX2 (Morgan et al., 1997), while the induction of cadmium resistance genes does not require $S \mathrm{kn} 7 \mathrm{p}$ (Lee et al., 1999). The data suggest that the cooperation between Yap1p and Skn7p is responsible for the control of a specific subset of genes induced during oxidative stress. The involvement of $\mathrm{Skn} 7 \mathrm{p}$ in cell cycle regulation and cell wall biosynthesis also suggests that these processes are partially coregulated. Interestingly, Yap1p has also been shown to activate the two glutathione biosynthesis genes $G S H 1$ and $G S H 2$ in response to temperature stress, indicating again the close association between different stress-responsive pathways (Sugiyama et al., 2000). This effect might however be indirect, since temperature increases enhance oxygen respiration and lead to increased generation of reactive oxygen species.

\section{The perception of specific stress conditions and the transmis- sion of the signal}

While a number of transcription factors activated in response to stress conditions have been identified, these factors (with the possible exception of Hsflp) are themselves not able to directly perceive stress conditions, and must be activated by dedicated pathways. The following section describes several of these pathways and their specific outcomes. The scope of this review does not allow consideration of all the relevant molecular events taking place during these stress responses, and focuses only on those most relevant to winemaking.

Perception and signal transduction during hyperosmotic stress: As described in the previous sections, the first serious stress condition experienced by $S$. cerevisiae during and after inoculation into grape must is probably a hyperosmotic shock, due to the high sugar content of must. The hyperosmotic pressure results in water efflux from the cell and subsequently diminished turgor pressure, which leads to rapid cell shrinkage (Hohmann, 1997). As in the case of heat shock, sudden exposure of an actively growing culture of $S$. cerevisiae to hyperosmotic conditions, for example through addition of salt to the final concentration of $6 \%$, leads to rapid death of up to $90 \%$ of the cells in a variety of strains tested. The survival rate in these conditions is, as for other stresses, growth phase dependent, with non-growing stationary phase cells showing much higher resistance than actively growing cultures (Blomberg \& Adler, 1992; Fuge \& Werner-Washburn, 1997). However, the sensitivity of strains to sudden changes in osmotic pressure is not correlated with their ability to grow in a high osmolarity substrate, since the same strains are well able to grow in media containing $10 \% \mathrm{NaCl}$. This suggests that two distinct molecular mechanisms are responsible for survival during sudden changes and for the long term adaptation to a high osmolarity substrate (Blomberg \& Adler, 1992; Hohmann, 1997). The ability to immediately respond to and survive sudden changes, which involves the so-called acute or immediate response, has received relatively little attention, and little information is available about specific mechanisms involved. Not surprisingly, data show that mutations resulting in defects in a number of cellular structures, including the cytoskeleton (Novick \& Botstein, 1985), the vacuole (Latterich \& Watson, 1993) and the cell wall result in osmosensitive strains, but little is known regarding specific factors involved. An example of a protein required for the acute response was recently described by Nass \& Rao (1999), who show that the endosomal/prevacuolar $\mathrm{Na}^{+} / \mathrm{H}^{+}$exchanger, $\mathrm{Nhx} 1 \mathrm{p}$, can confer osmotolerance following sudden hypertonic shock.

On the other hand, the long term adaptive response to hyperosmotic conditions has been intensively studied, and some of the major results of these studies are reviewed in the following section. The long term adaptive response is also of more relevance to the winemaking process. Yeast cells inoculated into grape must are not actively growing and have been preadapted to stress at the end of the production process. They therefore possess a high intrinsic resistance to sudden hyperosmotic shock. However, in order to grow, the cells have to adapt to the high osmotic pressure of the must. This long term adaptation requires the coordination of all major cellular processes and involves most cellular structures, including the cytoskeleton, the cellular membrane, the cell wall and the nucleus. The most prominent and studied response to hypertonic shock, however, is the induction of glycerol synthesis, a compatible solute which accumulates inside the cell in order to equilibrate osmotic pressure. The following section therefore focuses mainly on the processes required to increase intracellular glycerol concentration. Fig. 3 summarises schematically the interactions between the most important elements involved in this process.

The sensing of hyperosmotic stress: Hyperosmotic stress is perceived independently by at least two membrane-based sensing mechanisms, which both feed the signal into the same signaling pathway, the so-called high osmolarity glycerol (HOG) pathway (Fig. 3). The first element of the osmosensing machinery to be identified in $S$. cerevisiae was $\operatorname{Sin} 1 \mathrm{p}$, a protein with strong homology to bacterial two-component phosphorelay systems (Ota \& Varshavsky, 1993). Numerous phosphorelay systems have been described in prokaryotic organisms, where they act as sensors of the extracellular environment. However, the $S$. cerevisiae Sln1p was the first such sensor identified in eukaryotes. SLN1 encodes an autophosphorylating histidine kinase, and is part of a four-step phosphorelay system, involving two additional proteins, Ypd1p and Ssk1p (Posas et al., 1996). The relay is initiated by the autophosphorylation of $\operatorname{Sin} 1 \mathrm{p}$ on a histidine residue, followed by the transfer of the phosphate group to an aspartate residue on $S \ln 1 \mathrm{p}$, further transfers to a histidine residue in Ypd1p, and finally to an aspartate residue in Ssk1p. Ssk1p acts as a molecular switch or response regulator, which controls the downstream effects of the two-component system (Posas \& Saito, 1998).

The second osmosensing mechanism was identified by Maeda et al. (1995). It consists of the transmembrane protein Sholp, which associates directly with the downstream signal transduction module, consisting of a MAPK cascade. The exact mechanism through which Sholp activates this module is not yet understood. 


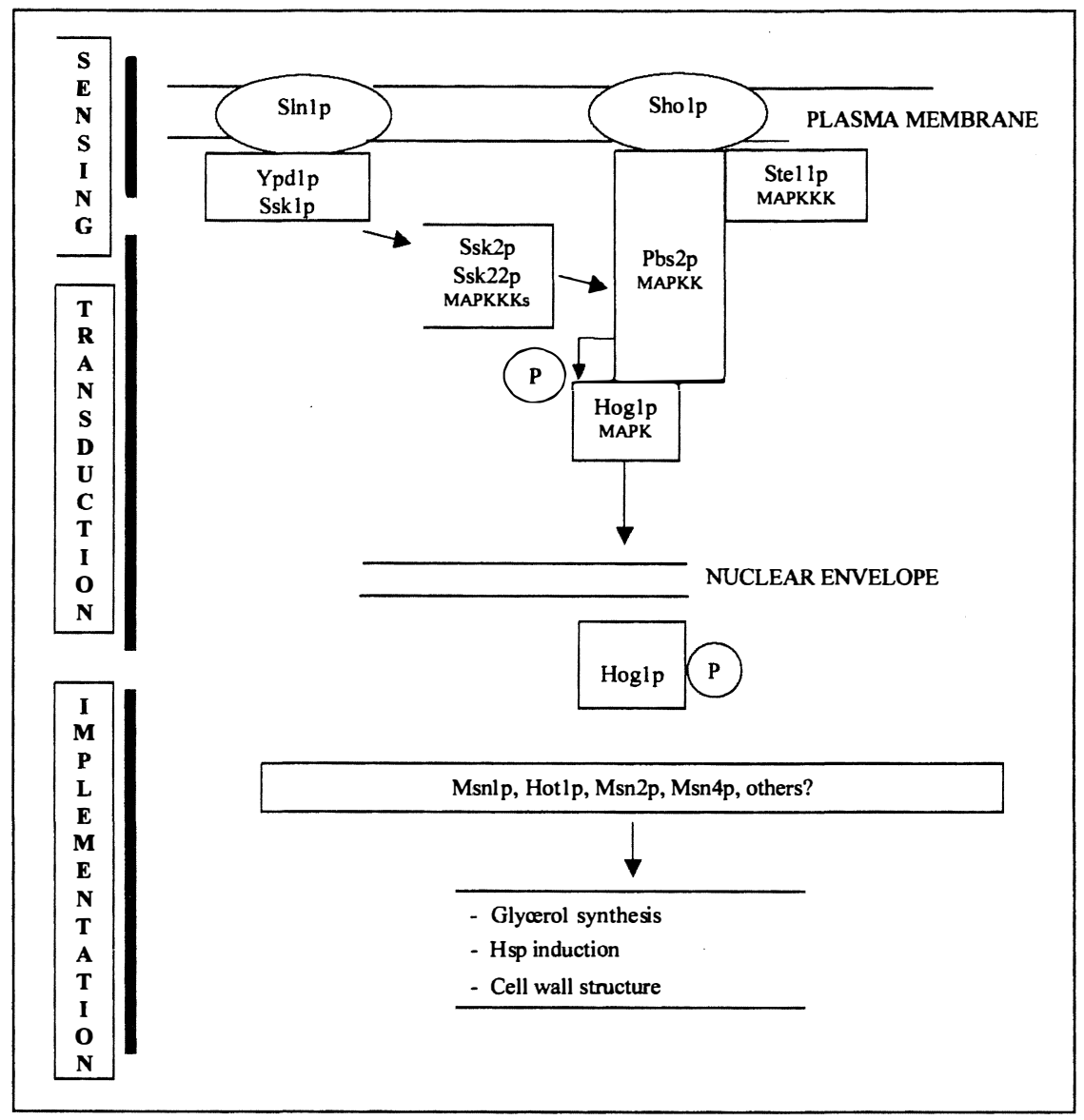

FIGURE 3

Schematic representation of the HOG signal transduction cascade. The two osmosensors, Sholp and the two-component phosphorelay system Sln1p/Ypd1p/Skn1p, activate the same MAP kinase cascade via two different MAPKKK, Ste11p and Ssk2p/Ssk22p, respectively. The MAPKK, Pbs2p, acts as a scaffold protein for the Sho1p/Ste11p sensing and signal transduction elements. After sequential phosphorylation within the cascade, the phosphorylated MAPK, Hog1p, is transferred into the nucleus, where it will phosphorylate as yet unknown target proteins.

The nature of the environmental signal which is perceived by the sensors during hyperosmotic stress has also not yet been identified. Several cellular, physical or chemical parameters are affected by hyperosmotic stress, and each of these, or a combination thereof, might be sensed by the cell. Potentially sensed parameters include in particular turgor pressure, water activity or waterflux across the membrane. Recent data by Tamas et al. (2000) suggest that the most relevant of these parameters is the change in turgor pressure.

Transduction - the HOG MAPK connection: Both high osmolarity sensors described above activate the same intermediate signal transduction module, the high osmolarity glycerol (HOG) MAPK cascade. MAPK cascades, also referred to as $\underline{e x t r a c e l l u-~}$ lar signal regulated kinases (ERK), are well conserved signal transduction modules found in all eukaryotic organisms. In S. cerevisiae, five such cascades have been identified, and all are required for the transmission of specific extracellular signals to the relevant compartments in the cell (Levin \& Errede, 1995; Banuett, 1998; Gustin et al., 1998; Garrington \& Johnson, 1999). These cascades are made up of three sequentially acting protein kinases, MAPKKK, MAPKK and MAPK. The complexity created through three sequential phosphorylation steps is thought to provide the cell with possibilities for signal amplification, multiple sites of signal integration and multiple sites for signal output. In the case of hyperosmotic shock, the situation is complicated by the fact that three kinases, Ssk2p, Ssk22p and Ste11p, act as MAPKKK. These three MAPKKK all activate the same MAPKK, encoded by the $P B S 2$ gene, and finally the MAPK, encoded by the HOGl gene. The cascade therefore results in the final phosphorylation of Hog $1 \mathrm{p}$, which activates or inactivates specific target proteins involved in the hyperosmotic stress response. However, no direct target for Hoglp-dependent phosphorylation has yet been identified. Ferrigno et al. (1998) and Reiser et al. (1999) have shown that Hog1p is transported into the nucleus as a consequence of hyperosmotic stress, suggesting that most targets are localised in the nucleus. In addition, Reiser $e t$ al. (1999) showed that the presence of Hog1p in the nucleus is significantly shortened in the absence of either Msn2p or Msn4p, two of the transcription factors required for the induction of hyperosmotic stress induced genes. The two factors therefore appear to mediate, at least in part, Hog1p-dependent transcriptional activation.

Mutations resulting in permanently phosphorylated Hog $1 \mathrm{p}$ are lethal, and Hog 1p phosphorylation is controlled by two protein 
phosphatases, encoded by the PTP2 and PTP3 genes. A deletion of both phosphatase genes results in hyperactivated Hog $1 \mathrm{p}$ (Maeda et al., 1994; Wurgler-Murphy et al., 1997).

Activation of the MAPK cascade by the two-component osmosensor is a result of the inhibition of the autophosphorylation of $\operatorname{Sln} 1 \mathrm{p}$ by hyperosmotic pressure, which leads to the dephosphorylation of the other elements of the phosphorelay system. The unphosphorylated regulator element of the two-component osmosensor Ssk1p physically interacts with Ssk2p, inducing conformational changes which leads to the autophosphorylation and subsequent activation of this MAPKKK, followed by activation of the MAPKK and MAPK (Posas \& Saito, 1998). Ssk22p is thought to be activated by the same mechanism.

The second osmosensor, Sholp, activates the MAPK cascade via a different MAPKKK, Ste11p (Posas \& Saito, 1997). Interestingly, the MAPKK Pbs2p appears to act as a scaffold protein for this cascade, since it physically interacts with both Sholp and Ste11p as well as Hog1p. The molecular details of the activation of Ste11p by Sholp are, however, not yet understood.

Molecular consequences of Hoglp activation: Several genes have been shown to be regulated in Hog $1 \mathrm{p}$-dependent mechanisms, including HSP12 encoding a small heat shock protein (Varela et al., 1995), the CTT1 catalase-encoding gene (Schüller et al., 1994), the GLO1 glyoxalase-encoding gene (Inoue et al., 1998) and GPD1, which encodes a protein required for the synthesis of glycerol, the main compatible solute synthesised by S. cerevisiae (Albertyn et al., 1994). The Hog1p-dependent regulation of most of these genes occurs at least in parts via the STRE elements found within the promoters of these genes, and is dependent upon Msn2p and Msn4p, as well as Hot1p and Msn1p (Rep et al., 1999, 2000). The induction of glycerol biosynthesis genes results in the accumulation of glycerol inside the cell which acts as a compatible solute and allows the equilibration of the osmotic pressure between the intracellular and extracellular environment, leading to the reestablishment of turgor pressure (Hohmann, 1997; Scanes et al., 1998). The accumulation of glycerol during hyperosmotic stress is of importance to the winemaking process, since this compound is quantitatively the most important byproduct of alcoholic fermentation, and is considered to have a beneficial impact on wine quality. It contributes in particular to the sweetness and fullness of the wine (Eustace \& Thornton, 1987; Ribéreau-Gayon et al., 2000). The regulation of glycerol biosynthesis therefore constitutes one of the targets of current yeast strain improvement strategies (Michnick et al., 1997; Scanes et al., 1998; Remize et al., 1999). However, these strategies, particularly attempts to increase glycerol production, have encountered problems due to the complex metabolic interactions between glycerol metabolism and other metabolic pathways, in particular with regard to the redox balance of the cell. A full understanding of all the relevant regulatory systems of glycerol metabolism should overcome these problems.

Other molecular responses: Not all molecular responses to hyperosmotic stress are the consequence of Hog1p-dependent signal transduction. An example of a Hog $1 \mathrm{p}$-independent response to osmotic stress is the inactivation or activation of Fps1p, a membrane channel protein which facilitates glycerol uptake and efflux (Luyten et al., 1995). The inactivation of the glycerol channel under hyperosmotic stress is required for effi- cient intracellular glycerol accumulation, and strains carrying mutated versions of Fps1p which still form channels but cannot be inactivated, are sensitive to hyperosmotic shock (Tamas et al., 1999). Fps1p is also required for the response to hypoosmotic shock, when glycerol must be released to maintain osmotic stability, and fpsl deletion mutants are sensitive to hypoosmotic shock (Tamas et al., 1999).

Response to changes in nutrient availability and nutrient limitation: After having adapted to the hyperosmotic environment of grape must, yeast cells start to ferment and grow, which requires the consumption of extracellular nutrients. Of all the environmental factors regulating cell growth and viability, the availability of nutrients has the most direct influence on cell physiology and long term survival. Unicellular organisms possess a limited internal nutritional storage capacity, and directly depend on the nutrients present in the surrounding environment. While the presence of an abundance of nutrients results in fast growth and the repression of stress-response pathways, the exhaustion of nutrients is perceived as a stress which requires specific adaptation to ensure survival (De Winde et al., 1997).

$S$. cerevisiae has developed a number of strategies to respond to the availability of specific nutrients and to adapt to and survive various types of nutrient limitation or starvation. Indeed, fermentative growth itself constitutes an obvious adaptation to the availability of a specific nutrient, glucose. Glucose has many profound effects on general yeast physiology, and directly or indirectly regulates all major metabolic pathways, some of which influence stress-response mechanisms. High levels of glucose result in fermentative growth which, on a molecular level, is characterised by the strong induction of genes encoding glycolytic enzymes (Müller et al., 1995) and hexose transporters (Özcan \& Johnston, 1995) through a process referred to as glucose induction (Johnston, 1999). Concomitantly, other metabolic pathways, in particular respiratory metabolism, are repressed through $\underline{c}$ arbon catabolite repression (CCR) (Gancedo, 1998; Carlson, 1999). $\mathrm{CCR}$ acts mainly on the level of gene transcription, and represses genes involved in respiration and other mitochondrial functions, as well as genes required for the utilisation of other carbon sources. The molecular identity of some of the main factors involved in the process of CCR is by now well established, and include transcription-repressor proteins and their regulators. Mig1p, a zinc finger protein that binds directly to the promoter of glucose-repressed genes and recruits the general repressor proteins Tup1p and Ssn6p, is the central factor responsible for the bulk of glucose-dependent repression (Ostling et al., 1996), and is controlled through phosphorylation by the kinase Snf1p (Carlson, 1999).

The induction of glycolytic genes and concomittant repression of respiratory metabolism results in the rapid utilisation of glucose and the accumulation of alcohol, and is thought to give $S$. cerevisiae, a relatively ethanol-resistant species, a selective advantage over other microorganisms in glucose-rich natural habitats. While fermentative growth can therefore be considered a specific adaptation to an evolutionary niche, other responses to nutrient availability are shared between several nutrients or, at the least, are using shared signaling components. This includes the responses to nitrogen and carbon-source limitation. The mechanisms involved in these processes are of obvious relevance for 
winemaking, since nitrogen limitation in particular is frequently responsible for stuck fermentations.

Fig. 4 presents a summary of the different adaptive responses to nutrient limitation and exhaustion. The complete depletion of one or more essential elements results in a coordinated growth arrest and entry into stationary phase (Fuge \& Werner-Washburn, 1997). Cells arrest their cell cycle during the non-budding G1 phase of the cycle and implement a number of molecular programmes to ensure survival. Adaptations include a general reduction in metabolic activity, the accumulation of reserve and stress protective carbohydrates like glycogen and trehalose, respectively, the induction of Hsps and the strengthening of the cell wall. This description applies to the stationary phase as observed under typical laboratory conditions, and it should be remembered that it differs fundamentally from the stationary phase occuring during wine fermentations. Growth arrest in the latter case is usually not a consequence of nutrient limitation, but rather of high levels of ethanol, and does not lead to a general shut-down of metabolic activity, since the glycolytic activity does not cease at this stage (Boulton et al., 1995). Nevertheless, Riou et al. (1997) and Puig \& Perez-Ortin (2000) have shown that several stress-regulated genes are also induced during growth arrest in the case of wine fermentations. It has also been suggested that the stationary phase during wine fermentation might be the result of a perceived nutrient limitation, created by the inabilty of the cells to take up nitrogenous compounds in a substrate containing high levels of ethanol. If this were the case, the two types of stationary phase might indeed be due to similar causes and share some of the signaling components involved.

Depending on the type of limitation and the specific circumstances, yeast cells may choose two other strategies to ensure survival. In the case of the complete exhaustion of both nitrogen and fermentable carbon sources, diploid and most polyploid cells are able to undergo meiosis, resulting in the formation of four spores within a protective envelope called an ascus (Mitchell, 1994). Spores are probably the most stress-resistant cell type of $S$. cere-

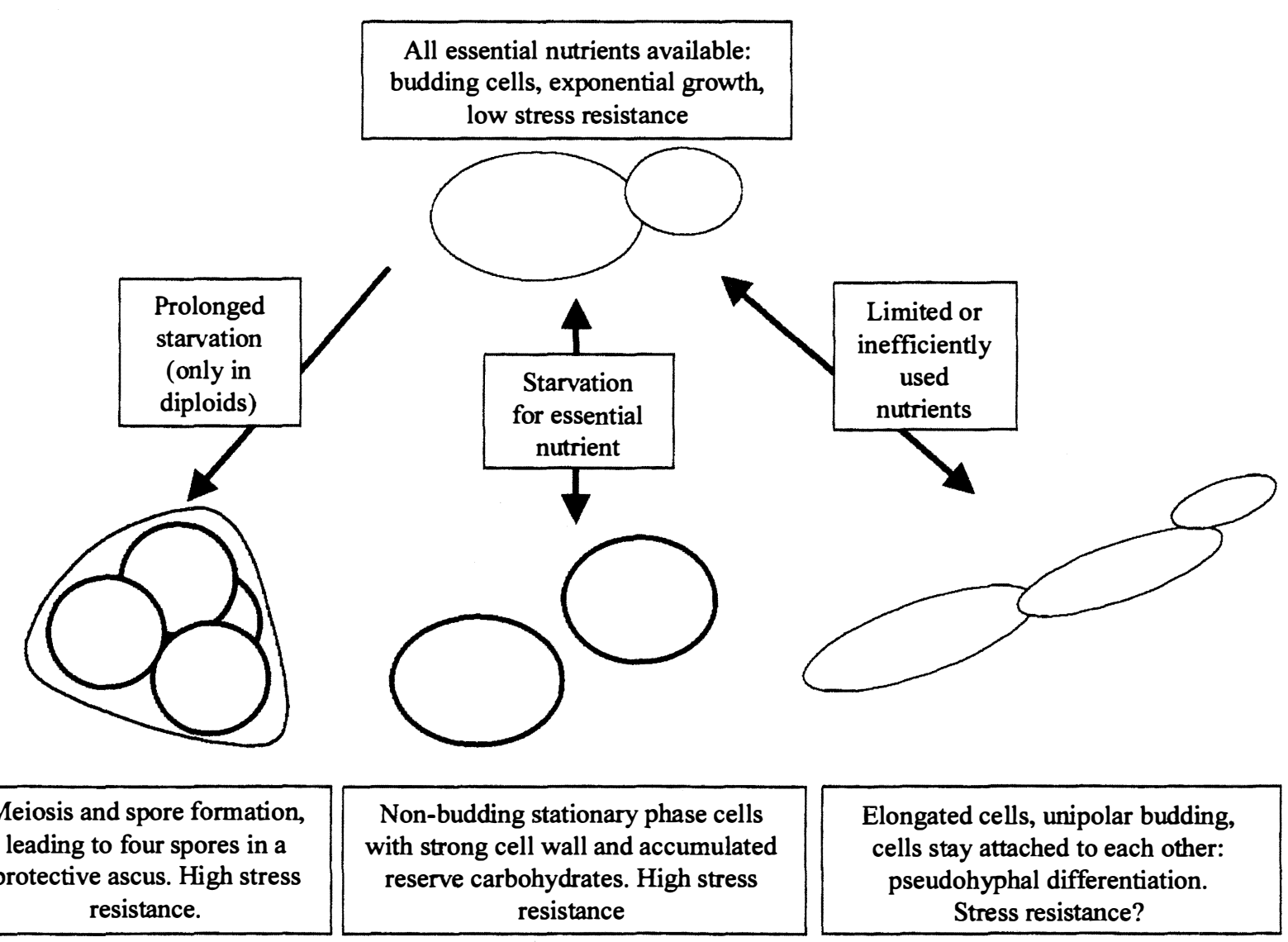

FIGURE 4

Cellular responses of $S$. cerevisiae to nutrient availabilty. 
visiae, and can lie dormant for prolonged periods until nutritional conditions have improved. A further nutrient-induced adaptation is the pseudohyphal growth response. This response is implemented when nutrients are limited, but not completely exhausted. In this case, the cells change their appearance from round or ovoid to thin and elongated, and will stay attached to each other after budding. The budding pattern also shifts from bipolar to unipolar, resulting in the formation of a hyphae-like structure called "pseudohypha". Pseudohyphae grow beyond the perimeter of the colony and are thought to be an adaptation allowing cells to search for nutrients (Gimeno et al., 1992; Vivier et al., 1997).

The choice of any of these specific developmental pathways depends on the specific environmental conditions and the genetic background of the strain. The different molecular steps, from the perception of the signal to the implementation of a molecular response, is discussed in the following section.

Sensing of glucose: Nutrient sensing in yeast and other organisms has frequently been associated with nutrient specific transporters, permeases, or homologues thereof (Kruckeberg et al., 1998). Until recently, however, little was known about the molecular mechanisms involved in the sensing of nutrient availability. In the last few years, several genes encoding receptor proteins that sense specific nutrients have been identified using genetic approaches. The best studied examples include receptors for glucose and ammonium ions.

The data show that extracellular glucose concentrations are monitored by at least three receptors, while additional internal sensors control the flux of glucose through the glycolytic pathway (Johnston, 1999; Thevelein \& De Winde, 1999). The existence of more than one sensor can probably be explained by the importance of glucose in the life cycle of S. cerevisiae, which requires that the cells not only be able to sense the presence, but also the precise amount of glucose present in the environment, necessitating sensors of various affinities. The three known glucose-sensing proteins are encoded by the RGT2, SNF3 and GPR1 genes. Both Rgt $2 p$ and Snf3p display strong homologies to hex-

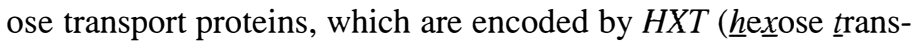
porter) genes, indicating a close evolutionary relationship between transporters and sensors (Johnston, 1999). However, both appear unable to transport glucose. These sensors are thought to specifically bind the monitored substance and to signal the concentration available according to the percentage of the receptor which is occupied. Snf3p is required for the induction of the high-affinity $H X T$ genes at low levels of glucose, while Rgt $2 p$ induces the low affinity transporters at high levels of extracellular glucose. Accordingly, Snf3p is supposed to represent a high affinity receptor, while Rgt $2 p$ would represent the low affinity variant. The signal appears to be transmitted through a long cytoplasmic $C$-terminal extension of the proteins, which is not normally found in $H X T$-encoded proteins (Özcan et al., 1998). This domain has recently been shown to interact with Std1p and Mth1p, two proteins required for the signaling process (Schmidt et al., 1999; Lafuente et al., 2000). It is, however, still unclear how the signal is transmitted to the nuclear components responsible for the induction of specific target genes. The signal created by $\mathrm{Snf} 3 \mathrm{p}$ and Rgt $2 \mathrm{p}$ results in efficient growth on glucose and has not been directly linked to any stress response related mechanisms.
A more direct connection between glucose sensing and stress response has been established for the third receptor, Gprlp (Yun et al., 1997; Colombo et al., 1998; Xue et al., 1998; Kraakman et al., 1999). This protein shows homology to a group of wellknown G-protein-coupled receptors, which act as sensors in a number of well established signal transduction pathways in all eukaryotes. In $S$. cerevisiae, a much studied example of such a receptor is found in the mating pathway. This receptor, encoded by either the STE2 or STE3 genes according to cell type, binds the pheromone of the opposite mating type and activates a MAPK cascade via a heterotrimeric, receptor-coupled G-protein (Kurjan, 1993). While genetic and physiological evidence suggests that Gprlp is able to perceive glucose, and may function as a direct receptor of this compound (Colombo et al., 1998; Kraakman et al., 1999), the exact molecular nature of this perception is not yet understood. Gprlp, however, clearly is the first G-protein associated receptor involved in the sensing of nutrients (Thevelein \& De Winde, 1999; Lorenz et al., 2000).

GPR1 was cloned in a two-hybrid screen by Yun et al. (1997) and Xue et al. (1998) using the $\alpha$-subunit of a receptor-coupled heterotrimeric G-protein, Gpa2p, as a bait. Heterotrimeric G-proteins are central elements in numerous signal transduction cascades and consist of three subunits, $\alpha, \beta$, and $\gamma$. Upon activation of the membrane-bound receptor, the $\alpha$-subunit of these proteins binds GTP which induces conformational changes resulting in the dissociation of the $\beta$ and $\gamma$ subunits and the transmission of the signal (Neer, 1995; Bolker, 1998). Before being associated with Gpr1p, Gpa2p had been implicated in a number of events related to the control of intracellular cAMP levels (Nakafuku et al., 1988; Papasavvas et al., 1992; Kübler et al., 1997; Lorenz \& Heitman, 1997; Colombo et al., 1998). Genetic data indeed suggest a close interaction of Gpa2p with the Ras proteins, small GTP-binding proteins with strong homology to the mammalian Ras oncogenes, whose main role in $S$. cerevisiae appears to be the control of adenylate cyclase, the enzyme synthesising cAMP (Broach, 1991). Genetic interactions include the ability of overexpressed GPA2 to suppress the growth defects of temperature sensitive ras mutants, and the non-viability of a strain carrying deletions of both RAS2 and GPA2 (Nakafuku et al., 1988; Papasavvas et al., 1992).

The transmission of the glucose-generated signal: Data suggest that Gpa2p is able to directly regulate the activity of the adenylate cyclase Cyr1p (Colombo et al., 1998; Xue et al., 1998). The cyclase had previously been thought to be mainly, or even uniquely, regulated by the two Ras proteins, since genetic and biochemical evidence suggested that most cAMP-dependent signals, including nutrient-dependent regulations, are Rasp-dependent. While genetic evidence still supports a role for Rasp in some nutrient-related signaling events, its precise regulation and function remain unclear. It is possible that the functions include the maintenance of basal cAMP levels in the cell, the response to intracellular acidification and the coordination or switching between signal transduction cascades during pseudohyphal differentiation (Thevelein \& De Winde, 1999; Lorenz et al., 2000). Indeed, basal cAMP levels are required for growth, and a strain deleted for either the $C Y R I$ gene, encoding the cyclase, or for both $R A S$ genes is inviable.

The only known cellular role of cAMP is to control the activi- 
ty of the cAMP-dependent kinase (PKA), an enzyme which consists of a regulatory and a catalytic subunit. The regulatory subunit, encoded by BCYI (Toda et al., 1987a), binds cAMP, which results in the dissociation of the regulatory and the catalytic subunits and activation of PKA. Three genes, TPKI-3, encode largely homologous versions of the catalytic subunit, and act redundantly in most processes (Toda et al., 1987b). However, recent data suggest that the three Tpkps have specific signaling functions during pseudohyphal growth and differentially regulate iron up-take as well as respiratory growth (Robertson \& Fink, 1998; Robertson et al., 2000). The mechanisms which impart this specificity are however not yet understood.

PKA activity is essential in S. cerevisiae, and high PKA activity favours glycolysis, growth and proliferation. However, mutant strains with a hyperactivated kinase activity, resulting for example from a mutation in $B C Y 1$ or a hyperactive allele of $R A S 2$, display hypersensitivity to stress conditions, failure to induce $H S P$ genes upon heat shock, and failure to enter stationary phase prop- erly or to induce the synthesis of glycogen and trehalose in response to nutrient depletion. Mutants with reduced PKA activity display the inverse phenotypes, in particular slow growth, increased stress resistance and higher levels of glycogen and trehalose. The level of PKA activity was also shown to strongly affect the oxidative stress response mediated by $5 \mathrm{kn} 7 \mathrm{p}$ (Charizanis et al., 1999), the level of osmo-tolerance and osmo-dependent gene expression (Norbeck \& Blomberg, 2000), as well as post-diauxic shift and nutrient limitation-dependent transcription (Tadi et al., 1999; Pedruzzi et al., 2000). The cAMP pathway therefore represents one of the central control systems balancing the need for efficient growth with the necessity of protecting the cells against the deleterious effects of various stresses. The general model of cAMP-dependent signal transduction is represented in Fig. 5.

As discussed in the section on the transcriptional induction of Hsps and other stress induced proteins, the failure of strains with hyperactivated PKA to properly respond to stress conditions or to

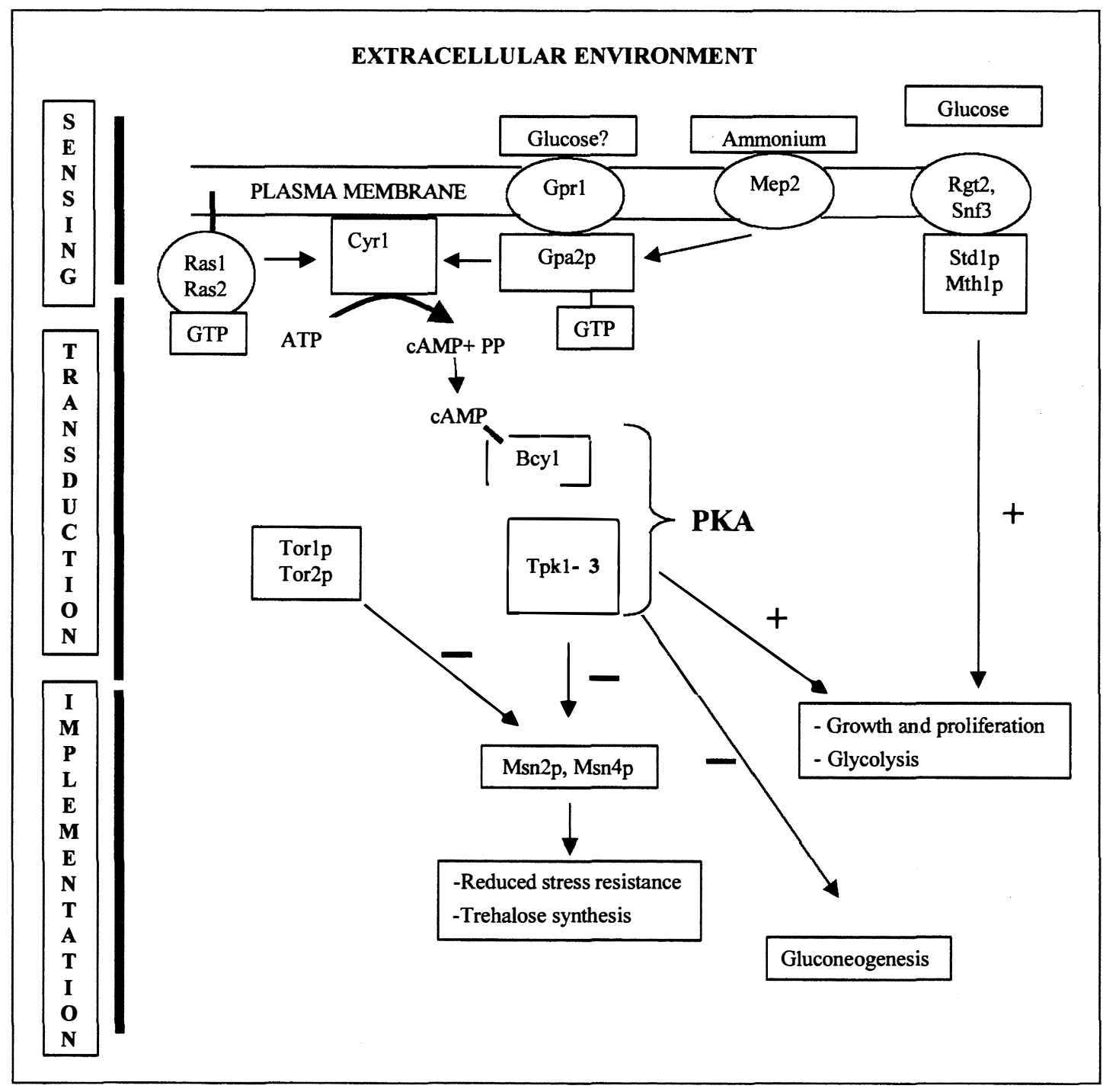

FIGURE 5

The central role of cAMP in nutrient signaling and the regulation of cellular metabolism. High levels of glucose and nitrogen sources lead to reduced stress resistance and increased growth and proliferation. The dissociation of the regulatory subunit of PKA, Bcy1p, from the catalytical subunit encoded by the TPK1-3 genes leads to increased kinase activity. 
accumulate trehalose is a result of the inhibition of the Msn2p/Msn4p-dependent induction of STRE-controlled genes (Thevelein \& De Winde, 1999). The link between the Gpr1p/Gpa2p-sensing system with cAMP/PKA and the transcriptional regulators $\mathrm{Msn} 2 \mathrm{p} / \mathrm{Msn} 4 \mathrm{p}$ therefore provides an integrated model for nutrient sensing, growth control and stress resistance, providing an insight into the coordination between these two fundamental processes.

The sensing of a preferred nitrogen source, ammonium: Ammonium is one of the preferred nitrogen sources of $S$. cerevisiae, and is present in grape must at variable concentrations. It also plays a central role in the regulation of nitrogen metabolism, since it is the main intermediate between catabolic and anabolic pathways (Ter Schure et al., 2000). It is therefore one of the first nitrogen sources to disappear from the substrate during cellular growth, which requires the cells to switch to a less preferred nitrogen source. Data by Lorenz and Heitman (1998b) show that the ammonium transporter Mep2p is required for the sensing of ammonium, and does not play any role in the sensing of other nitrogen sources. Three ammonium permeases with significant sequence homologies, Mep1p, Mep2p and Mep3p, have been identified in S. cerevisiae (Marini et al., 1997). Of the three, Mep2p presents the highest affinity $\left(K_{\mathrm{M}}=1-2 \mu \mathrm{M}\right)$ for ammonium. A deletion of the $M E P 2$ gene results in cells incapable of filamentous growth in ammonium-limited medium. The $\Delta m e p 2$ strain, however, is perfectly able to form filaments in response to limitations in other nitrogen sources like glutamine, asparagine or proline. The deletion does not result in any growth defects on media containing ammonium, showing that the two additional ammonium permeases Mep1p and Mep3p are efficient transporters, but play a less prominent role in signaling of ammonium availability.

The data suggest that yeast cells probably require specific sensors for each essential nutrient, including a variety of nitrogen and carbon sources. Several other permeases can be expected to play a similar role and to specifically signal the presence or limited availability of their substrates. However, only indirect evidence has been provided so far (Lorenz \& Heitman, 1998b).

Current knowledge strongly favours the hypothesis that Mep2p, similar to Gprlp, transmits the signal via Gpa2p. However, no direct interaction of Gpa2p with Mep2p has so far been demonstrated. Genetic evidence nevertheless suggests that Mep2p requires Gpa2p for signaling (Lorenz \& Heitman, 1998a, b), suggesting that both carbon source and nitrogensource-dependent signals are transmitted at least in part by the same signaling elements, in particular the cAMP-dependent kinase.

Other nitrogen sources have recently been shown to be sensed by permease-like sensors. For example, the GRRl encoded protein presents homologies to permeases and acts as a sensor of extracellular amino acids (Iraqui et al., 1999).

Other nutrient dependent signalling systems, like the Tor $1 \mathrm{p}$ and Tor $2 p$ kinases-dependent activation of cell growth in response to nutrient availability exist. This system sequesters transcription factors that are required for the induction of stress responses, including Msn2p/Msn4p, in the cytoplasm when sufficient nutrients are available, and therefore directly contributes to the decreased stress resistance observed in rich growth media (Beck \& Hall, 1999).

Responses to the accumulation of ethanol: After having survived hyperosmotic stress, variations in temperature and nutrient availability, and other detrimental conditions, the yeast is confronted with an additional hurdle: its own metabolic activity has resulted in the accumulation of a highly toxic substance, ethanol.

The sensing or perception of ethanol per se has not been elucidated. The existence, however, of ethanol-specific sensors similar in nature to the ones described for glucose or ammonium is improbable. Ethanol-dependent stress responses are probably indirectly induced by the perception of damage or water availability rather than through a specific sensing system (Hallsworth, 1998). Besides having a general effect on yeast physiology by inhibiting growth (Thomas \& Rose, 1979) and affecting membrane fluidity (Thomas et al., 1978), several specific molecular consequences of high ethanol concentrations have been described. They include, for example, an alteration of vacuolar morphology and endocytosis (Meaden et al., 1999), a change in membrane lipid composition (Thomas et al., 1978; Alexandre et al., 1994; Arneborg et al., 1995), the induction of HSP genes (Piper et al., 1994) and an inhibition of some enzymatic activities (Lopes et al., 1999).

Most research has focused on the changes in lipid composition and the protective effects of some of the membrane components against ethanol stress. Thomas et al. (1978) showed that the enrichment of the plasma membrane with the double unsaturated $\mathrm{C}_{18}$ fatty acid linoleyl resulted in higher resistance to ethanol than enrichment with the mono-unsaturated $\mathrm{C}_{18}$ fatty acid oleyl. They also showed that enrichments with combinations of ergosterol, the only sterol naturally produced by $S$. cerevisiae, and specific fatty acids had similarily beneficial effects. The same group likewise demonstrated that ethanol concentrations lowered the rate of solute accumulation of glucose and amino acids like lysine and arginine (Thomas \& Rose, 1979). Recent data suggest that lipid composition has an important influence on stress tolerance in general, and that resistance levels are probably determined by the ratio of different lipid components rather than by a simple, linear correlation between the amount of specific lipids and stress tolerance.

Alexandre et al. (1994) presented data suggesting that increases in the proportion of ergosterol and in unsaturated fatty acids levels are responsible for ethanol tolerance. This link between the desaturation of fatty acids and ethanol resistance was further strengthened through data by Kajiwara et al. (1996), who showed that a strain of $S$. cerevisiae transformed with a $\Delta-12$ fatty acid desaturase gene from Arabidopsis thaliana, which does not naturally occur in the yeast, contains a high level of polyunsaturated fatty acids in the membrane, and that this increase is accompanied by an increased resistance to ethanol. Sajbidor et al. (1995) also showed that ethanol induces the synthesis of ergosterol and leads to an increase in the ratio of unsaturated fatty acids, in particular palmitoleate and oleate, over their saturated counterparts, palmitate and stearate. Finally, research by Chi \& Ameborg (1999) showed that the more ethanol-tolerant of two strains of $S$. cerevisiae contained a higher ergosterol/phospholipid ratio, a higher incorporation of long chain fatty acids and a slightly higher proportion of unsaturated fatty acids. However, data by Swan 
\& Watson (1997) seem to suggest that there is no obvious relationship between membrane fluidity, fatty acyl composition and stress tolerance, and that the enrichment of membranes with oleic acid (18:1) results in higher stress resistance than enrichment with linoleic acid (18:2), at least in a $\Delta-9$ desaturase deficient strain (Swan \& Watson, 1999). Nevertheless, the data suggest a consistent role for membrane lipid composition in stress resistance, and show a stronger correlation of stress resistance with membrane lipid composition than with either the accumulation of Hsps or trehalose.

Besides the increase in ergosterol, fatty acid chain length and the level of desaturation, two Hsps, Hsp30p, an integral membrane protein, and Hsp12p, associated with membranes, have been shown to play specific roles during ethanol stress. Hsp12p appears to protect membrane integrity during both dessication and ethanol stress through a mechanism that is not yet understood (Sales et al., 2000), whereas Hsp30p regulates the plasma membrane $\mathrm{H}^{+}$-ATPase. This ATPase consumes a large part of the ATP produced by the cell, pumping $\mathrm{H}^{+}$ions out of the cytoplasm to maintain intracellular $\mathrm{pH}$ and the proton gradient across the plasma membrane. The importance of the mechanism for the maintenance of transport, in particular of nitrogenous compounds, has been described in a previous section. While the amount of ATPase in the plasma membrane diminishes after ethanol and other stresses, the remaining proteins are strongly activated, resulting in a net increase of ATP consumed. Hsp30p has been shown to control and reduce ATPase activity (Braley \& Piper, 1997), and the authors suggest an energy conserving role for the protein.

Overall, the molecular response to ethanol stress is very similar to the response observed during heat shock. A similar set of Hsps is induced, which, in addition to the above-mentioned HSP 30 and HSP 12 genes, includes HSP104, the product of which has been shown to contribute to both heat shock and ethanol tolerance. The general effects of high temperature and high ethanol on the plasma membrane appear identical, and both can lead to problems in protein folding or protein denaturation (Piper, 1995). Both also require the induction of anti-oxidant enzymes, since increased temperature and high ethanol lead to the accumulation of some reactive oxygen species. The similarities suggest that both processes are perceived by similar mechanisms, and the observations on the perception of heat shock and the transcriptional activation of heat shock proteins therefore should apply to ethanol stress responses as well.

\section{CONCLUSIONS}

Fermentation predictability and wine quality are directly dependent on wine yeast attributes that assist in the rapid establishment of numerical dominance in the early phase of wine fermentation, and that determine the ability to conduct an even and efficient fermentation with a desirable residual sugar level. It is therefore not surprising that the primary selection criteria applied to most wine yeast strain development programmes relate to the overall objective of achieving an efficient conversion of grape sugar to alcohol and carbon dioxide, at a controlled rate and without the development of off-flavours. Both the genetic and physiological stability of stock cultures of seed yeast and wine yeast starter cultures are essential to optimal fermentation performance. The physiological stability and "fitness" of active dried wine yeast cultures relate to the maintenance of cell viability (the relative proportion of living cells within an active dried starter culture) and vitality (the measure of metabolic activity, relating to the vigour of an active dried starter culture) during the process of yeast manufacturing (including desiccation and storage), as well as biological resilience during wine fermentation. Fermentation efficiency of an active dried wine yeast starter culture is also directly correlated with the strain's ablity to withstand sudden environmental change and unfavourable growth conditions. A direct link between stress resistance (the ability of a strain to adapt efficiently to a changing environment) and the ability to bring grape must fermentation to a rapid and successful end has been clearly demonstrated.

This review provides only a glimpse of the vast amount of data that has been accumulated in the last decades regarding the control of stress response mechanisms and their importance for the industrial application of yeast. The molecular pathways described were chosen for their relevance to the winemaking process as well as for their functions as representatives of the mechanisms of stress responses and signal transduction, not only in yeast but all eukaryotic organisms, providing a broad idea of our current knowledge in these important areas of biological investigation.

Several other relevant pathways, including the so-called cell integrity pathway which responds to hypoosmotic shock (Hohmann, 1997), the fermentable growth $\underline{\text { media }}$ (FGM) induced pathway (Thevelein \& De Winde, 1999) and the oxidative stressresponse pathway (Jamieson, 1998) are not discussed due to space limitations. Furthermore, the toxic effects of heavy metals, in particular copper (Avery et al., 1996; Howlett \& Avery, 1997), have only been briefly mentioned. However, all of these pathways rely on molecular modules and cellular adaptations that are very similar to the ones described in this review. The cell integrity pathway, for example, relies on a MAPK cascade to transmit the signal to downstream transcription factors, the FGM pathway is largely controlled by cAMP, and heavy metal resistance is dependent on changes in the cellular membrane similar to those observed during ethanol stress.

The main aim of the study of stress responses in the yeast $S$. cerevisiae has been to increase our knowledge of fundamental biological processes. $S$. cerevisiae has proven to be an excellent and versatile model organism, permitting, due to its relative biological simplicity and the availability of a unique set of molecular tools, study of the complex interactions which govern the relationship between an organism and its environment. The research has led to several important breakthroughs, and has given insights into cellular processes which are of major importance, particularly in the medical field. For example, it is largely due to the insights provided by research conducted on $S$. cerevisiae that we are beginning to understand the complex interaction between signal receptors, signaling pathways and effector proteins, a field of major importance for human health, since many of these pathways are involved in processes which result in diseases. These include in particular most aspects of oncogenesis as well as genetic metabolic disorders, and numerous drugs specifically affect targets within these pathways.

While the reasons to pursue this research are obvious in the medical field, biotechnological advances based on these data have yet to make an impact. The potential for targeted improvements of stress resistance and other linked aspects of industrial 
strains, be it wine yeast strains, brewing strains or baking strains, has not yet been fully realised. As pointed out in this review, stress resistance is of major industrial importance, and a small improvement in, for example, ethanol tolerance could result in major industrial improvements. A general improvement in stress resistance would also help to address several problems plaguing the wine industry, in particular by reducing the incidence of stuck or sluggish fermentation. Some approaches, based on the already accumulated knowledge in the molecular network underlying stress resistance, have shown promising results, and genetically engineered strains with improved stress resistance have been obtained. Kim et al. (1996) presented data showing that a strain deleted for the gene encoding a trehalose hydrolysing enzyme, acid trehalase $(A T H 1)$, contained higher levels of trehalose and showed better survival after dehydration, freezing and ethanol shock, while Shima et al. (1999) presented a similar approach based on trehalase mutants. However, other attempts to increase stress resistance through increased trehalose production have failed, and the link between trehalose content and stress resistance does not appear to be linear. As stated by Randez-Gil et al. (1999) in a review on baker's yeast, there is room for improvement for the engineering of industrial yeast.

There is fundamentally only one reason for the relatively slow progress and the absence of important and visible improvements in the field, and this reason lies in the intrinsic complexity of the mechanisms of stress resistance. Indeed, as this review has tried to highlight, stress resistance is governed by an interwoven, complex network of pathways, with numerous levels of control by feed-back systems, cross-talks and apparent redundancies. This system of checks and balances is required to balance the partially contradictory requirements of all life forms, to ensure the survival of the individual while maintaining efficient growth and a fast reproduction rate.

Truly improved stress resistance, based on a sound and targeted scientific approach, will only become achievable when this network is fully understood. Without a full understanding of all molecular interactions, most attempts in the field will remain akin to shots in the dark. However, there is light at the end of the tunnel. The goal of a full understanding of these pathways has been brought into reach by the progress in research methodology over the last years. Particularly since the publication of the entire genome of $S$. cerevisiae, several systematic methodologies have become available, and have by now matured sufficiently to be used on a wide scale in research laboratories throughout the world. These methodologies, which include microarray and DNA chip technology, allowing genome-wide transcription analysis (Cox et al., 1999), have created an entirely new scientific field, "genomics", which is quickly followed by "proteomics", the systematic analysis of protein-protein interaction. They allow, with the help of powerful software programs, the analysis of the molecular consequences of specific genetic defects or specific environmental conditions, providing a picture of all the genetic and physical interactions at a given moment as well as their evolution over time.

These technologies are now being applied to wine yeast strains and to the precise conditions found during wine fermentations. The first data based on such systematic approaches have been published (Puig \& Perez-Ortin, 2000; Rachidi et al., 2000;
Tanghe et al., 2000). More of these data will become available in the near future, and will result in endless opportunities to exploit newly discovered connections and interactions, and finally in new yeast strains tailor-made for specific purposes.

Developments of this nature are not welcomed by everyone. There are some deep-seated fears and worries about the possible consequences, both in ethical and environmental terms, of these powerful new approaches. While these fears appear largely limited to the agronomic biotechnology sector, and do not seem to touch the medical sector, which uses the same technology, they are nevertheless real and have to be addressed in a responsible, scientifically sound way. In the long term, there is little doubt that the potential benefits of the technology far outweigh the perceived risks. Living organisms, as this review has also tried to highlight, are not static entities, but permanently evolving and changing. DNA transfer, within and between species, is happening every day, all the time in nature. The changes that biotechnologists intend to introduce are all designed to improve specific characteristics of certain organisms for a specific industrial purpose. These changes could be achieved over a much longer time through different strategies, including traditional methods based on breeding and selection. Humans have, unconsciously, already bred over several millenniums the yeast species we are using today, which are so incredibly efficient in converting grape sugars into alcohol. However, all studies show that these industrial yeast strains have had a very limited, non-measurable impact on the surrounding environment. Even where released in largest numbers, for example at winery waste sites, very few of these yeast are found in the vineyard the following year (Khan et al., 2000; Van der Westhuizen et al., 2000a, b). While this does not imply that biotechnological advances are without dangers, it clearly demonstrates that properly monitored, targeteted improvement of yeast strains through genetic engineering is a promising route for the future (Pretorius, 2000).

\section{LITERATURE CITED}

ALBERTYN, J., HOHMANN, S., THEVELEIN, J.M. \& PRIOR, B.A., 1994. GPD1, which encodes glycerol-3-phosphate dehydrogenase, is essential for growth under osmotic stress in Saccharomyces cerevisiae, and its expression is regulated by the high-osmolarity glycerol pathway. Mol. Cell. Biol. 14, 4135-4144.

ALEXANDRE, H., ROUSSEAUX, I. \& CHARPENTIER, C., 1994. Ethanol adaptation mechanisms in Saccharomyces cerevisiae. Biotechnol. Appl. Biochem. 20, 173-183.

AMBESI, A., MIRANDA, M., PETROV, V.V. \& SLAYMAN, C.W., 2000. Biogenesis and function of the yeast plasma-membrane $\mathrm{H}(+)$-ATPase. J. Exp. Biol. 203, 155-160.

ARNEBORG, N., HOY, C.E. \& JORGENSEN, O.B., 1995. The effect of ethanol and specific growth rate on the lipid content and composition of Saccharomyces cerevisiae grown anaerobically in a chemostat. Yeast 11, 953-959.

ATTFIELD, P.V., 1997. Stress tolerance: the key to effective strains of industrial baker's yeast. Nat. Biotechnol. 15, 1351-1357.

AVERY, S.V., HOWLETT, N.G. \& RADICE, S., 1996. Copper toxicity towards Saccharomyces cerevisiae: dependence on plasma membrane fatty acid composition. Appl. Environ. Microbiol. 62, 3960-3966.

BANUETT, F., 1998. Signalling in the yeasts: An informational cascade with links to the filamentous fungi. Microbiol. Mol. Biol. Rev. 62, 249-274.

BEAVAN, M.J.C., CHARPENTIER, C. \& ROSE, A.H., 1982. Production and tolerance to ethanol in relation to phospholipid fatty-acyl composition of Saccharomyces cerevisiae. J. Gen. Microbiol. 128, 1447-1455.

BECK, T. \& HALL, M.N., 1999. The TOR signalling pathway controls nuclear localization of nutrient-regulated transcription factors. Nature 402, 689-692. 
BISSON, L.F., 1999. Stuck and sluggish fermentations. Am. J. Enol. Vitic. 50, 107-119.

BLOMBERG, A. \& ADLER, L., 1992. Physiology of osmotolerance in fungi. Adv. Microb. Physiol. 33, 145-212.

BOLKER, M., 1998. Sex and crime: heterotrimeric G proteins in fungal mating and pathogenesis. Fungal Genet. Biol. 25, 143-156.

BOORSTEIN, W.R \& CRAIG, E.A., 1990. Regulation of a yeast $H S P 70$ gene by a cAMP responsive transcriptional control element. EMBO J. 9, 2543-53.

BOSCHEINEN, O., LYCK, R., QUEITSCH, C., TREUTER, E., ZIMARINO, V. \& SCHARF, K.D., 1997. Heat stress transcription factors from tomato can functionally replace $H S F l$ in the yeast Saccharomyces cerevisiae. Mol. Gen. Genet. 255, 322-331.

BOULTON, R.B., SINGLETON, V.L., BISSON, L.F. \& KUNKEE, R.E., 1995. Principles and Practices of Winemaking. Chapman Hall, New York.

BOY-MARCOTTE, E., LAGNIEL, C.G., PERROT, M., BUSSEREAU, F., BOUDSOCQ, A., JACQUET, M. \& LABARRE, J., 1999. The heat shock response in yeast: differential regulations and contributions of the Msn2p/Msn4p and Hsf1p regulons. Mol. Microbiol. 33, 274-283.

BOY-MARCOTTE, E., PERROT, M., BUSSEREAU, F., BOUCHERIE, H. \& JACQUET, M., 1998. Msn2p and Msn4p control a large number of genes induced at the diauxic transition which are repressed by cyclic AMP in Saccharomyces cerevisiae. J. Bacteriol. 180, 1044-1052.

BRALEY, R. \& PIPER, P.W., 1997. The C-terminus of yeast plasma membrane $\mathrm{H}^{+}$-ATPase is essential for the regulation of this enzyme by heat-shock protein HSP30, but not for stress activation. FEBS Lett. 418, 123-126.

BROACH, J.R., 1991. Ras-regulated signaling processes in Saccharomyces cerevisiae. Curr. Opinion Genet. Dev. 1, 370-377.

BROWN, J.L., NORTH, S. \& BUSSEY, H., 1993. SKN7, a yeast multicopy suppressor of a mutation affecting cell wall beta-glucan assembly, encodes a product with domains homologous to prokaryotic two-component regulators and to heat shock transcription factors. J. Bacteriol. 175, 6908-6915.

CARLSON, M., 1999. Glucose repression in yeast. Curr. Opin. Microbiol. 2, 202-207.

CHARIZANIS, C., JUHNKE, H., KREMS, B. \& ENTIAN, K.D., 1999. The oxidative stress response mediated via Pos9/Skn7 is negatively regulated by the Ras/PKA pathway in Saccharomyces cerevisiae. Mol. Gen. Genet. 261, 740-752. CHI, Z. \& ARNEBORG, N., 1999. Relationship between lipid composition, frequency of ethanol-induced respiratory deficient mutants, and ethanol tolerance in Saccharomyces cerevisiae. J. Appl. Microbiol. 86, 1047-1052.

CHIRICO, W.J., WATERS, M.G., BLOBEL, G., 1988. 70K heat shock related proteins stimulate protein translocation into microsomes. Nature 332, 805-810.

COLOMBO, S., MA, P., CAUWENBERG, L., WINDERICKX, J., CRAUWELS, M., TEUNISSEN, A., NAUWELAERS, D., DE WINDE, J.H., GORWA, M.F., COLAVIZZA, D. \& THEVELEIN, J.M., 1998. Involvement of distinct G-proteins, Gpa2p and Ras, in glucose- and intracellular acidification-induced cAMP signaling in the yeast Saccharomyces cerevisiae. EMBO J. 17, 3326-3341.

COOPER, T.G., 1982a. Nitrogen metabolism in Saccharomyces cerevisiae. In: STRATHERN, J.N., JONES, E.W. \& BROACH, J.R. (eds). The molecular biology of the yeast Saccharomyces, vol. 2. Metabolism and gene expression. Cold Spring Harbor Laboratory, Cold Spring Harbor, New York. pp. 39-99.

COOPER, T.G., 1982b. Transport in Saccharomyces cerevisiae. In: STRATHERN, J.N., JONES, E.W. \& BROACH, J.R. (eds). The molecular biology of the yeast Saccharomyces, vol. 2. Metabolism and gene expression. Cold Spring Harbor Laboratory, Cold Spring Harbor, New York. pp. 399-462.

COX, K.H., PINCHAK, A.B. \& COOPER, T.G., 1999. Genome-wide transcription analysis in $S$. cerevisiae by mini-array membrane hybridization. Yeast $\mathbf{1 5}$, 703-713.

DE GROOT, E., BEBELMANN, J.P., MAGER, W·H. \& PLANTA, R.J., 2000. Very low amounts of glucose cause repression of the stress-responsive gene HSPI2 in Saccharomyces cerevisiae. Microbiology 146, 367-375.

DELTEIL, D. \& AIZAC, T., 1989. Yeast inoculation techniques with a marked yeast strain. Pract. Winery Vineyard May/June, 43-47.

DESHAIES, R.J., KOCH, B.D., WERNER-WASHBURNE, M., CRAIG, E.A. \& SCHEKMAN, R., 1988. A subfamily of stress proteins facilitates translocation of secretory and mitochondrial precursor polypeptides. Nature 332, 800-805.
DE WINDE, J.H. \& THEVELEIN, J.M., 1997. From feast to famine: adaptation to nutrient depletion in yeast. In: HOHMANN, S. \& MAGER, W.H. (eds). Yeast stress responses. R.G. Landes Company, Austin. pp. 7-52.

DINIZ-MENDES, L., BERNARDES, E., DE ARAUJO, P.S., PANEK, A.D. \& PASCHOALIN, V.M., 1999. Preservation of frozen yeast cells by trehalose. Biotechnol. Bioeng. 65, 572-578.

DUINA, A.A., KALTON, H.M. \& GABERT, R.F., 1998. Requirements for Hsp90 and a CyP-40 cyclophilin in negative regulation of the heat shock response. J. Biol. Chem. 273, 18974-18978.

ELEUTHERIO, E.C., RIBEIRO, M.J. PEREIRA, M.D., MAIA, F.M. \& PANEK, A.D., 1995. Effect of trehalose during stress in a heat-shock resistant mutant of Saccharomyces cerevisiae. Biochem. Mol. Biol. Int. 36, 1217-1223.

EUSTACE, R. \& THORNTON, R.J., 1987. Selective hybridiation of wine yeasts for higher yields of glycerol. Can. J. Microbiol. 33, 112-117.

FERRIGNO, P., POSAS, F., KOEPP, D., SAITO, H. \& SILVER, P., 1998. Regulated nucleo/cytoplasmic exchange of HOG1 MAPK requires the importin $\beta$ homologs NMD5 and XPO1. EMBO J. 17, 5606-5614.

FLEET, G.H., 1993. Yeast growth during fermentation. In: FLEET, G.H. (ed). Wine microbiology and biotechnology. Harwood Academic Publishers, Chur. pp. 27-54.

FUGE, E.K. \& WERNER-WASHBURN, M., 1997. Stationary phase in the yeast Saccharomyces cerevisiae. In: HOHMANN, S. \& MAGER, W.H. (eds). Yeast stress responses. R.G. Landes Company, Austin. pp. 53-74.

FUGELSANG, K.C., 1997. Wine Microbiology. Chapman \& Hall, New York.

GANCEDO, J.M., 1998. Yeast carbon catabolite repression. Microbiol.Mol. Biol. Rev. 62, 334-361.

GARRINGTON, T.P. \& JOHNSON, G.L., 1999. Organization and regulation of mitogen-activated protein kinase signaling pathways. Curr. Opin. Cell. Biol. 11, 211-218.

GEYMONAT, M., WANG, L., GARREAU, H. \& JACQUET, M., 1998. Ssa1p chaperone interacts with the guanine nucleotide exchange factor of ras Cdc25p and controls the cAMP pathway in Saccharomyces cerevisiae. Mol. Microbiol. 30, 855-864.

GIMENO, C.J., LJUNGDAHL, P.O., STYLES, C.A. \& FINK, G.R., 1992. Unipolar cell divisions in the yeast $S$. cerevisiae lead to filamentous growth: regulation by starvation and RAS. Cell 68, 1077-1090.

GLOVER, J.R. \& LINDQUIST, S., 1998. Hsp104, Hsp70, and Hsp40: a novel chaperone system that rescues previously aggregated proteins. Cell 94, 73-82.

GÖRNER, W., DURCHSCHLAG, E., MARTINEZ-PASTOR, M.T., ESTRUCH, F., AMMERER, G., HAMILTON, B., RUIS, H. \& SCHULLER, C., 1998. Nuclear localisation of the $\mathrm{C}_{2} \mathrm{H}_{2}$ zinc finger protein Msn2p is regulated by stress and protein kinase A activity. Genes Dev. 12, 586-597.

GUSTIN, M.C., ALBERTYN, J., ALEXANDER, M., \& DAVENPORT, K., 1998. MAP kinase pathways in the yeast Saccharomyces cerevisiae. Microbiol. Mol. Biol. Rev. 62, 1264-1300.

HALLSWORTH, J.E., 1998. Ethanol-induced water stress in yeast. J. Ferment. Bioeng. 85, 125-137.

HÄNNINEN, A.L., SIMOLA, M., SARIS, N. \& MAKAROW, M., 1999. The cytoplasmic chaperone $\mathrm{Hsp104}$ is required for conformational repair of heat-denatured proteins in the yeast endoplasmic reticulum. Mol. Biol. Cell 10, 3623-3632.

HARDY, J.A., WALSH, S.T. \& NELSON, H.C., 2000. Role of an alpha-helical bulge in the yeast heat shock transcription factor. J. Mol. Biol. 295, 393-409.

HENSCHKE, P.A., 1998. Stuck fermentation: causes, prevention and cure. ASVO Seminar, Advances in juice clarification and yeast inoculation. pp. 30-38.

HOHMANN, S., 1997. Shaping up: the response of yeast to osmotic stress. In: HOHMANN, S. \& MAGER, W.H. (eds). Yeast stress responses. R.G. Landes Company, Austin. pp. 101-145.

HOWLETT, N.G. \& AVERY, S.V., 1997. Induction of lipid peroxidation during heavy metal stress in Saccharomyces cerevisiae and influence of plasma membrane fatty acid unsaturation. Appl. Environ. Microbiol. 63, 2971-2976.

INOUE, Y., TSUJIMOTO, Y. \& KIMURA, A., 1998. Expression of the glyoxalase I gene of Saccharomyces cerevisiae is regulated by high osmolarity glycerol mitogen-activated protein kinase pathway in osmotic stress response. J. Biol. Chem. 273, 2977-2983. 
IRAQUI, I., VISSERS, S., BERNARD, F., DE CRAENE, J.-O., BOLES, E., URRESTARAZU, A. \& ANDRE, B., 1999. Amino acid signaling in Saccharomyces cerevisiae: a permease-like sensor of external amino acids and Fbox protein Grrlp are required for transcriptional induction of the $A G P I$ gene, which encodes a broad-specificity amino acid permease. Mol. Cell. Biol. 19, 989-1001.

IVORRA, C., PEREZ-ORTIN, J.E. \& DEL OLMO M.I., 1999. An inverse correlation between stress resistance and stuck fermentations in wine yeasts. A molecular study. Biotechnol. Bioeng. 64, 698-708.

JAKOBSEN, B.K \& PELHAM, H.R., 1988. Constitutive binding of yeast heat shock factor to DNA in vivo. Mol. Cell. Biol. 8, 5040-5042.

JAMIESON, D.J., 1998. Oxidative stress responses of the yeast Saccharomyces cerevisiae. Yeast 14, 1511-1527.

JENSEN, R.E. \& JOHNSON, A.E., 1999. Protein translocation: is Hsp70 pulling my chain? Curr. Biol. 9, 779-782.

JOHNSTON, M., 1999. Feasting, fasting and fermenting: glucose sensing in yeast and other cells. Trends Genet. 15, 29-33.

KHAN, W., AUGUSTYN, O.P.H., VAN DER WESTHUIZEN, T.J., LAMBRECHTS, M.G. \& PRETORIUS, I.S., 2000. Geographic distribution and evaluation of Saccharomyces cerevisiae strains isolated from vineyards in the warmer in-land regions of the Western Cape in South Africa. S. Afr. J. Enol. Vitic. (in press)

KAJIWARA, S., SHIRAI, A., FUJII, T., TOGURI, T., NAKAMURA, K. \& OHTAGUTCHI, K., 1996. Polyunsaturated fatty acid biosynthesis in Saccharomyces cerevisiae: expression of ethanol tolerance and the FAD2 gene from Arabidopsis thaliana. Appl. Environ. Microbiol. 62, 4309-4313.

KAYE, F.J., MODI, S., IVANOVSKA, I., KOONIN, E.V., THRESS, K., KUBO, A., KORNBLUTH, S. \& ROSE, M.D., 2000. A family of ubiquitine-like proteins binds the ATPase domain of Hsp70-like Stch. FEBS Lett. 467, 348-355.

KNIGHT, S.A., SEPURI, N.B., PAIN, D. \& DANCIS, A., 1998. Mt-Hsp70 homolog, Ssc2p, required for maturation of yeast frataxin and mitochondrial iron homeostasis. J. Biol. Chem. 273, 18389-18393.

KIM, J., ALIZADEH, P., HARDING, T., HEFNER-GRAVINK, A. \& KLIONSKY, D.J., 1996. Disruption of the yeast ATHI gene confers better survival after dehydration, freezing, and ethanol shock: potential commercial applications. Appl. Environ. Microbiol. 62, 1563-1569.

KOBAYASHI, N. \& McENTEE, K., 1990. Evidence for a heat shock transcription factor-independent mechanism for heat shock induction of transcription in Saccharomyces cerevisiae. Proc. Natl. Acad. Sci. USA 87, 6550-6554.

KOBAYASHI, N. \& McENTEE, K., 1993. Identification of cis and trans components of a novel heat shock stress regulatory pathway in Saccharomyces cerevisiae. Mol. Cell. Biol. 13, 248-256.

KONDO, K. \& INOUYE, M., 1991. TIP1, a cold shock-inducible gene of Saccharomyces cerevisiae. J. Biol. Chem. 266, 17537-17544.

KRAAKMAN, L.S., WINDERICKX, J., THEVELEIN, J.M. \& DE WINDE JH., 1999. Structure-function analysis of yeast hexokinase: structural requirements for triggering cAMP signalling and catabolite repression. Biochem. J. 343, 159-168. KRALLISH, I., JEPPSON, H., RAPOPORT, A. \& HAHN-HÄGERDAL, B., 1997. Effect of xylitol and trehalose on dry resistance of yeasts. Appl. Microbiol. Biotechnol. 47, 447-451.

KRAUS, J.K., REED, G., \& VILLETAZ, J.C., 1983. Levures seches actives de vinification 1re partie: fabrication et charcteristiques. Conn. Vigne Vin. 18, 93103.

KRAUS, J.K., REED, G., \& VILLETAZ, J.C., 1984. Levures seches actives de vinification 2e partie et fin: utilisation et evaluation. Conn. Vigne Vin. 18, 1-26.

KREMS, B., CHARIZANIS, C. \& ENTIAN, K.D., 1996. The response regulatorlike protein Pos9/Skn7 of Saccharomyces cerevisiae is involved in oxidative stress resistance. Curr: Genet. 29, 327-334.

KRUCKEBERG, A.L., WALSH, M.C. \& VAN DAM, K., 1998. How do yeast cells sense glucose? Bioessays. 20, 972-976.

KÜBLER, E., MÖSCH, H.U., RUPP, S. \& LISANTI, M.P., 1997. Gpa2p, a Gprotein alpha-subunit, regulates growth and pseudohyphal development in Saccharomyces cerevisiae via a cAMP-dependent mechanism. J. Biol.Chem. 272, 20321-20323.

KUGE, S. \& JONES, N., 1994. YAP1 dependent activation of TRX2 is essential for the response of Saccharomyces cerevisiae to oxidative stress by hydroperoxides. EMBO J. 13, 655-664.
KURJAN, J., 1993. The pheromone response pathway in Saccharomyces cerevisiae. Annu. Rev. Genet. 27, 147-179.

LAFUENTE, M.J., GANCEDO, C., JAUNIAUX, J.C. \& GANCEDO, J.M., 2000. Mth1 receives the signal given by the glucose sensors Snf3 and Rgt2 in Saccharomyces cerevisiae. Mol. Microbiol. 35, 161-172.

LATTERICH, M. \& WATSON, M.D., 1993. Evidence for a dual osmoregulatory mechanism in the yeast Saccharomyces cerevisiae. Biochem. Biophys. Res. Commun. 191, 1111-1117.

LEE, J., GODON, C., LAGNIEL, G., SPECTOR, D., GARIN, J., LABARRE, J. \& TOLEDANO, M.B., 1999. Yap1 and Skn7 control two specialzed oxidative stress response regulons in yeast. J. Biol. Chem. 23, 16040-16046.

LEE, Y.R., NAGAO, R.T. \& KEY, J.L., 1994. A soybean 101-kd heat shock protein complements a yeast $\mathrm{Hsp} 104$ deletion mutant in acquiring thermotolerance. Plant. Cell 6, 1889-1897.

LEVIN, D.E. \& ERREDE, B., 1995. The proliferation of MAP kinase signaling pathways in yeast. Curr: Opin. Cell. Biol. 7, 197-202.

LEWIS, M.J. \& PELHAM, H.R., 1985. Involvement of ATP in the nuclear and nucleolar functions of the $70 \mathrm{kd}$ heat shock protein. EMBO J. 4, 3137-3143.

LINDQUIST, S. \& CRAIG, E.A., 1988. The heat-shock proteins. Annu. Rev. Genet. 22, 631-677.

LINDQUIST, S. \& KIM, G., 1996. Heat-shock protein 104 expression is sufficient for thermotolerance in yeast. Proc. Natl. Acad. Sci. USA 93, 5301-5306.

LIU, X.D., LIU, P.C., SANTORO, N. \& THIELE, D.J., 1997. Conservation of a stress response: human heat shock transcription factors functionally substitutes for yeast HSF. EMBO J. 16, 6466-6477.

LOPES, D.H., MEYER-FERNANDES, J.R. \& SOLA-PENNA, M., 1999. Effects of trehalose and ethanol on yeast cytosolic pyrophosphatase. Z. Naturforsch. 54, 186-190.

LORENZ, M.C. \& HEITMAN, J., 1997. Yeast pseudohyphal growth is regulated by GPA2, a G protein $\alpha$ homolog. EMBO J. 16, 7008-7018.

LORENZ, M.C. \& HEITMAN, J., 1998a. Regulators of pseudohyphal differentiation in Saccharomyces cerevisiae identified through multicopy suppressor analysis in ammonium permease mutant strains. Genetics 150, 1443-1457.

LORENZ, M.C. \& HEITMAN, J., 1998b. The MEP2 ammonium permease regulates pseudohyphal differentiation in Saccharomyces cerevisiae. EMBO J. 17, 1236-1247.

LORENZ, M.C., PAN, X, HARASHIMA, T., CARDENAS, M.E. XUE, Y., HIRSCH, J.P. \& HEITMAN, J., 2000. The G protein-couled receptor Gpr1 is a nutrient sensor that regulates pseudohyphal differentiation in Saccharomyces cerevisiae. Genetics 154, 609-622.

LUYTEN, K.K.J., ALBERTYN, J., SKIBBE, W.F., PRIOR, B.A., RAMOS, J., THEVELEIN, J.M. \& HOHMANN, S., 1995. Fps1, a yeast member of the MIP family of channel proteins, is a facilitator for glycerol uptake and efflux and is inactive under osmotic stress. EMBO J. 14, 1360-1371

MAEDA, T., TAKEKAWA, M. \& SAITO, H., 1995. Activation of yeast PBS2 MAPKK by MAPKKKs or by binding of an SH3-containing osmosensor. Science 269, 554-558.

MAEDA, T., WURGLER-MURPHY, S.M. \& SAITO, H., 1994. A two-component system that regulates an osmosensing MAP kinase cascade in yeast. Nature 369, 242-245.

MAGER, H.M. \& DE KRUIJFF, A.J.J., 1995. Stress-induced transcriptional activation. Microbiol. Rev. 59, 506-531.

MAGER, W.H. \& HOHMANN, S., 1997. Stress response mechanisms in the yeast Saccharomyces cerevisiae. In: HOHMANN, S. \& MAGER, W.H. (eds). Yeast stress responses. R.G. Landes Company, Austin. pp. 1-5.

MARCHLER, G., SCHULLER, C., ADAM, G. \& RUIS, H., 1993. A Saccharomyces cerevisiae UAS element controlled by protein kinase A activates transcription in response to a variety of stress conditions. EMBO J.12, 19972003.

MARINI, A.M., SOUSSI-BOUDEKOU, S., VISSERS, S. \& ANDRE, B., 1997. A family of ammonium transporters in Saccharomyces cerevisiae. Mol. Cell. Biol. 17, 4282-4293.

MARTINEZ-PASTOR, M.T., MARCHLER, G., SCHULLER, C., MARCHLERBAUER, A., RUIS, H. \& ESTRUCH, F., 1996. The Saccharomyces cerevisiae zinc finger proteins Msn2p and Msn4p are required for transcriptional induction through the stress response element (STRE). EMBO J. 15, 2227-2235. 
MEADEN, P.G., ARNEBORG, N., GULDFELDT, L.U., SIEGUMFELDT, H. \& JACOBSEN, M., 1999. Endocytosis and vacuolar morphology in Saccharomyces cerevisiae are altered in response to ethanol stress or heat shock. Yeast 15, 1211-1222.

MICHNICK, S., ROUSTAN, J.L., REMIZE, F., BARRE, P. \& DEQUIN, S. 1997. Modulation of glycerol and ethanol yields during alcoholic fermentation in Saccharomyces cerevisiae strains overexpressed or disrupted for GPDl encoding glycerol 3-phosphate dehydrogenase. Yeast 13, 783-793.

MITCHELL, A.P., 1994. Control of meiotic gene expression in Saccharomyces cerevisiae. Microbiol. Rev. 58, 56-70.

MONTEIRO, F.F. \& BISSON, L., 1991a. Amino acid utilization and urea formation during vinification fermentations. Am. J. Enol. Vitic. 42, 199-208.

MONTEIRO, F.F. \& BISSON, L., 1991b. Biological assay of nitrogen content of grape juice and prediction of sluggish fermentation. Am. J. Enol. Vitic. 42, 47-57. MONTEIRO, F.F. \& BISSON, L., 1992a. Nitrogen supplementation of grape juice. I. Effect on amino acid utilization during fermentation. Am. J. Enol. Vitic. 43, 1-10.

MONTEIRO, F.F. \& BISSON, L., 1992b. Nitrogen supplementation of grape juice. II. Effect on amino acid and urea release following fermentation. Am. $J$. Enol. Vitic. 43, 11-17.

MORADAS-FERREIRA, P., COSTA, V., PIPER, P. \& MAGER, W., 1996. The molecular defences against reactive oxygen species in yeast. Mol. Microbiol. 19, 651-658.

MORANO, K.A., LIU, P.C. \& THIELE, D.J., 1998. Protein chaperones and the heat shock response in Saccharomyces cerevisiae. Curr. Opin. Microbiol. 1, 197-203.

MORANO, K.A., SANTORO, N., KOCH, K.A. \& THIELE, D.J., 1999. A transactivation domain in yeast heat shock transcription factor is essential for cell cycle progression during stress. Mol. Cell. Biol. 19, 402-411.

MORGAN, B.A., BANKS, G.R., TOONE, W.M., RAITT, D., KUGE, S. \& JOHNSTON, L.H., 1997. The Skn7 response regulator controls gene expression in the oxidative stress response of the budding yeast Saccharomyces cerevisiae. EMBO J. 16, 1035-1044.

MORGAN, B.A., BOUQUIN, N., MERRILL, G.F. \& JOHNSTON, L.H., 1995 A yeast transcription factor bypassing the requirement for SBF and DSC1/MBF in budding yeast has homology to bacterial signal transduction proteins. $E M B O$ J. 14, 5679-5689.

MORTIMER, R.K., ROMANO, P., SUZZI, G. \& POLSINELLI, M., 1994. Genome renewal: a new phenomenon revealed from a genetic study of 43 strains of Saccharomyces cerevisiae derived from natural fermentation of grape musts. Yeast 10, 1543-1552.

MOSKVINA, E., SCHULLER, C., MAURER, C.T., MAGER, W.H. \& RUIS, H., 1998. A search in the genome of Saccharomyces cerevisiae for genes regulated via stress response elements. Yeast 14, 1041-1050.

MÜLLER, S., BOLES, E., MAY, M. \& ZIMMERMANN, F.K., 1995. Different internal metabolites trigger the induction of glycolytic gene expression in Saccharomyces cerevisiae. J. Bacteriol. 177, 4517-4519.

NAKAFUKU, M., OBARA, T., KAIBUCHI, K., MIYAJIMA, I., MIYAJIMA, A., ITOH, H., NAKAMURA, S., ARAI, K., MATSUMOTO, K. \& KAZIRO, Y., 1988. Isolation of a second yeast Saccharomyces cerevisiae gene (GPA2) coding for guanine nucleotide-binding regulatory protein: studies on its structure and possible functions. Proc. Natl. Acad. Sci. USA 85, 1374-1378.

NASS, R. \& RAO, R., 1999. The yeast endosomal $\mathrm{Na}^{+} / \mathrm{H}^{+}$exchanger, $\mathrm{Hhx} 1$, confers osmotolerance following acute hypertonic shock. Microbiology 145, 3221-3228.

NATHAN, D.F., VOS, M.H. \& LINDQUIST, S., 1997. In vivo functions of the Saccharomyces cerevisiae Hsp90 chaperone. Proc. Natl. Acad. Sci. USA 94, 12949-12956.

NEER, E.J., 1995. Heterotrimeric G proteins: organizers of transmembrane signals. Cell 80, 249-257.

NIETO-SOTELO, J., WIEDERRECHT, G., OKUDA, A. \& PARKER, C.S., 1990. The yeast heat shock transcription factor contains a transcriptional activation domain whose activity is repressed under nonshock conditions. Cell $\mathbf{6 2}$, 807-817.

NORBECK, J. \& BLOMBERG, A., 2000. The level of cAMP-dependent protein kinase A activity strongly affects osmotolerance and osmo-instigated gene expression changes in Saccharomyces cerevisiae. Yeast 16, 121-137.
NOVICK, P. \& BOTSTEIN, D., 1985. Phenotypic analysis of temperature-sensitive yeast actin mutants. Cell 40, 405-416.

NWAKA, S., MECHLER, B., VON AHSEN, O. \& HOLZER, H., 1996. The heat shock factor and mitochondrial Hsp70 are necessary for survival of heat shock in Saccharomyces cerevisiae. FEBS Lett. 399, 259-263.

OSTLING, J., CARLBERG, M. \& RONNE, H., 1996. Functional domains in the Mig1 repressor. Mol. Cell. Biol. 16, 753-761

OTA, I.M. \& VARSHAVSKY, A., 1993. A yeast protein similar to bacterial two-component regulators. Science 262, 566-569.

OUGH, C.S., HUANG, Z., AN, D. \& STEVENS, D., 1991. Amino acid uptake by four commercial yeasts at two different temperatures of growth and fermentation: effects on urea excretion and reabsorption. Am. J. Enol. Vitic. 42, 26-40.

ÖZCAN, S., DOVER, J. \& JOHNSTON, M., 1998. Glucose sensing and signaling by two glucose receptors in the yeast Saccharomyces cerevisiae. EMBO J. 17, 2566-2573.

ÖZCAN, S. \& JOHNSTON, M., 1995. Three different regulatory mechanisms enable yeast hexose transporter (HXT) genes to be induced by different levels of glucose. Mol. Cell. Biol. 15, 1564-1572.

PAMMENT, N.B., 1989. Overall kinetics and mathematical modeling of ethanol inhibition in yeasts. In: VAN UDEN, N. (ed). Alcohol toxicity in yeast and bacteria. CRC Press, Pearl River, New York. pp. 1-75.

PAPASAVVAS, S., ARKINSTALL, S., REID, J. \& PAYTON, M., 1992. Yeast alpha-mating factor receptor and G-protein-linked adenylyl cyclase inhibition requires RAS2 and GPA2 activities. Biochem. Biophys. Res. Commun. 184, 1378-1385.

PARK, J.I., GRANT, C.M., ATTFIELD, P.V. \& DAWES, I.W., 1997. The freeze-thaw stress response of the yeast Saccharomyces cerevisiae is growth phase specific and is controlled by nutritional state via the $R A S$-cyclic AMP signal transduction pathway. Appl. Environ. Microbiol. 63, 3818-3824.

PARSELL, D.A., KOWAL, A.S., SINGER, M.A. \& LINDQUIST, S., 1994. Protein disaggregation mediated by heat-shock protein Hsp104. Nature 372, 475-478.

PEDRUZZI, I., BÜRCKERT, N., EGGER, P. \& DE VIRGILIO, C., 2000. Saccharomyces cerevisiae Ras/cAMP pathway controls post-diauxic shift element-dependent transcription through the zinc finger protein Gis1. EMBO J. 19, 2569-2579.

PETERING, J.E., HENSCHKE, P.A. \& LANGRIDGE, P., 1991. The Escherichia coli $\beta$-glucuronidase gene as a marker for Saccharomyces yeast strain identification. Am. J. Enol. Vitic. 42, 6-12.

PIPER, P.W., 1995. The heat shock and ethanol stress responses of yeast exhibit extensive similarity and functional overlap. FEMS Microbiol. Lett. 134, 121-127. PIPER, P.W., 1997. The yeast heat shock response. In: HOHMANN, S. \& MAGER, W.H. (eds). Yeast stress responses. R.G. Landes Company, Austin. pp. 75-99.

PIPER, P.W., ORTIZ-CALDERON, C., HOLYOAK, C., COOTE, P. \& COLE, M., 1997. Hsp30, the integral plasma membrane heat shock protein of Saccharomyces cerevisiae, is a stress-inducible regulator of plama membrane $\mathrm{H}^{+}$-ATPase. Cell. Stress Chaperones 2, 12-24.

PIPER, P.W., TALREJA, K., PANARETOU, B., MORADAS-FERREIRA, P., BYRNE, K., PRAEKELT, U.M., MEACOCK, P., RECNACQ, M. \& BOUCHERIE, H., 1994. Induction of major heat-shock proteins of Saccharomyces cerevisiae, including plasma membrane Hsp30, by ethanol levels above a critical threshold. Microbiology 140, 3031-3038.

POIRIER, I., MARECHAL, P.A., RICHARD, S. \& GERVAIS, P., 1999. Saccharomyces cerevisiae viability is strongly dependent on rehydration kinetics and the temperature of dried cells. J. Appl. Microbiol. 86, 87-92.

POSAS, F. \& SAITO, H., 1997. Osmotic activation of the HOG MAPK pathway via Ste11p MAPKKKK: scaffold role of Pbs2p MAPKK. Science 276, 1702-1705. 
POSAS, F. \& SAITO, H., 1998. Activation of the yeast SSK2 MAP kinase kinase kinase by SSK1 two-component response regulator. EMBO J. 17, 1385-1394.

POSAS, F., WURGLER-MURPHY, S.M., MAEDA, T., WITTEN, E.A., THAI, T.C. \& SAITO, H., 1996. Yeast HOG1 MAP kinase cascade is regulated by a multistep phosphorelay mechanism in the SLN1-YPD1-SSK1 "two-component" osmosensor. Cell 86, 865-875.

PRAEKELT, U.M. \& MEACOCK, P.A., 1990. HSP12, a new small heat shock gene of Saccharomyces cerevisiae: analysis of structure, regulation and function. Mol. Gen. Genet. 223, 97-106.

PRETORIUS, I.S., 2000. Tailoring wine yeast for the new millennium: novel approaches to the ancient art of wine making. Yeast 16, 675-729.

PRETORIUS, I.S., VAN DER WESTHUIZEN, T.J. \& AUGUSTYN, O.P.H., 1999. Yeast biodiversity in vineyards and wineries and its importance to the South African wine industry. S. Afr. J. Enol. Vitic. 20, 61-79.

PUIG, S. \& PEREZ-ORTIN, J.E., 2000. Stress response and expression patterns in wine fermentations of yeast genes induced at the diauxic shift. Yeast 16, 139-148.

RABINDRAN, S.K., HAROUN, R.I., CLOS, J., WISNIEWSKI, J. \& WU, C., 1993. Regulation of heat shock factor trimer formation: role of a conserved leucine. Science 259, 230-234.

RACHIDI, N., BARRE, P. \& BLONDIN, B., 2000. Examination of the transcriptional specificity of an enological yeast. A pilot experiment on the chromosomeIII right arm. Curr. Genet. 37, 1-11.

RANDEZ-GIL, F., SANZ, P. \& PRIETO, J.A., 1999. Engineering baker's yeast: room for improvement. Trends Biotechnol. 17, 237-244.

REISER, V., RUIS, H. \& AMMERER, G., 1999. Kinase activity-dependent nuclear export opposes stress induced nuclear accumulation and retention of Hog 1 mitogen-activated protein kinase in the budding yeast Saccharomyces cerevisiae. Mol. Biol. Cell 10, 1147-1161.

REMIZE, F., ROUSTAN, J.L., SABLAYROLLES, J.M., BARRE, P. \& DEQUIN, S., 1999. Glycerol overproduction by engineered Saccharomyces cerevisiae wine yeast strains leads to substantial changes in by-product formation and to a stimulation of fermentation rate in stationary phase. Appl. Environ. Microbiol. 65, 143-149.

REP, M., ALBERTYN, J., THEVELEIN, J.M., PRIOR, B.A. \& HOHMANN, S., 1999. Different signalling pathways contribute to the control of GPDI expression by osmotic stress in Saccharomyces cerevisiae. Microbiology 145, 715-727.

REP, M., REISER, V., GARTNER, U., THEVELEIN, J.M., HOHMANN, S., AMMERER, G. \& RUIS, H., 2000. Osmotic stress-induced gene expression in Saccharomyces cerevisiae requires Msn $1 \mathrm{p}$ and the novel nuclear factor Hot $1 \mathrm{p}$. Mol. Cell. Biol. 19, 5474-5485.

RIBÉREAU-GAYON, J., DUBOURDIEU, D., DONÈCHE, B. \& LONVAUD, A., 2000. Conditions of yeast development. In: Handbook of enology. John Wiley \& Sons Ltd, London. pp. 75-106.

RIBÉREAU-GAYON, J., PEYNAUD, E., SUDRAUD, P. \& RIBÉREAUGAYON, P., 1972. Traité d'oenologie. In: Science et technique du vin. Dunod, Paris. p. 340.

RIOU, C., NICAUD, J.M., BARRE, P. \& GAILLARDIN, C., 1997. Stationary-phase gene expression in Saccharomyces cerevisiae during wine fermentation. Yeast 13, 903-915.

ROBERTSON, L.S., CAUSTON, H.C., YOUNG, R.A. \& FINK, G.R., 2000. The yeast A kinases differentially regulate iron uptake and respiratory function. Proc. Natl. Acad. Sci. USA 97, 5984-5988.

ROBERTSON, L.S. \& FINK, G.R., 1998. The three yeast A kinases have specific signaling functions in pseudohyphal growth. Proc. Natl. Acad. Sci. USA 95, 13783-13789.

RUIS, H. \& SCHÜLLER, C., 1995. Stress signalling in yeast. Bioessays 17, 959-965.

SAJBIDOR, J., CIESAROVA, Z. \& SMOGROVICOVA, D., 1995. Influence of ethanol on the lipid content and fatty acid composition of Saccharomyces cerevisiae. Folia Microbiol. 40, 508-510.

SALES, K., BRANDT, W., RUMBAK, E. \& LINDSEY, G., 2000. The LEA-like protein HSP12 in Saccharomyces cerevisiae has a plasma membrane location and protects membranes against desiccation and ethanol-induced stress. Biochim. Biophys. Acta 1463, 267-278.

SAMUEL, D., 1996. Investigation of ancient Egyptian baking and brewing methods by correlative microscopy. Science $\mathbf{2 7 3}, 488-490$.
SANCHEZ, Y. \& LINDQUIST, S., 1990. Hsp104 required for induced thermotolerance. Science 248, 1112-1115.

SANCHEZ, Y., TAULIEN, J., BORKOVICH, K.A. \& LINDQUIST, S., 1992. Hsp104 is required for tolerance to many forms of stress. EMBO J. 11, 2357-2364. SCANES, K.T., HOHMANN, S. \& PRIOR, B.A., 1998. Glycerol production by the yeast Saccharomyces cerevisiae and its relevance to wine: a review. S. Afr. J. Enol. Vitic. 19, 17-24.

SCHMIDT, M.C., McCARTNEY, R.R., ZHANG, X., TILLMAN, T.S., SOLIMEO, H., WOLFL, S., ALMONTE, C. \& WATKINS, S.C., 1999. Std1 and Mth1 proteins interact with the glucose sensors to control glucose-regulated gene expression in Saccharomyces cerevisiae. Mol. Cell. Biol. 19, 4561-4571.

SCHMITT, A.P. \& McENTEE, K., 1996. Msn2p, a zinc finger DNA-binding protein, is the transcriptional activator of the multistress response in Saccharomyces cerevisiae. Proc. Natl. Acad. Sci. USA 93, 5777-5782.

SCHÜLLER, C., BREWSTER, J.L., ALEXANDER, M.R., GUSTIN, M.C. \& RUIS, H., 1994. The HOG pathway controls osmotic regulation of transcription via the stress response element (STRE) of the Saccharomyces cerevisiae CTTI gene. EMBO J. 13, 4382-4389.

SERRANO, R., 1993. Structure, function and regulation of plasma membrane $\mathrm{H}(+)$-ATPase. FEBS Lett. 325, 108-111.

SEYMOUR, I.J. \& PIPER, P.W., 1999. Stress induction of HSP30, the plasma membrane heat shock protein gene of Saccharomyces cerevisiae, appears not to use known stress-regulated transcription factors. Microbiology 145, 231-239.

SHIMA, J., HINO, A., YAMADA-IYO, C., SUZUKI, Y., NAKAJIMA, R., WATANABE, H., MORI, K., TAKANO, H., 1999. Stress tolerance in doughs of Saccharomyces cerevisiae trehalase mutants derived from commercial baker's yeast. Appl. Environ. Microbiol. 65, 2841-2846.

SIDERIUS, M. \& MAGER, W.H., 1997. General stress response: in search of a common denominator. In: HOHMANN, S. \& MAGER, W.H. (eds). Yeast stress responses. R.G. Landes Company, Austin. pp. 213-230.

SIMON, J.R., TREGER, J.M. \& MCENTEE, K., 1999. Multiple independent regulatory pathways control UB14 expression after heat shock in Saccharomyces cerevisiae. Mol. Microbiol. 31, 823-832.

SLANINOVA, I., SESTAK, S., SVOBODA, A. \& FARKAS, V., 2000. Cell wall and cytoskeleton reorganization as the response to hyperosmotic shock in Saccharomyces cerevisiae. Arch. Microbiol. 173, 245-252.

SMITH, A., WARD, M.P. \& GARRET, S., 1998. Yeast PKA represses Msn2p/Msn4p-dependent gene expression to regulate growth, stress response and glycogen accumulation. EMBO J. 17, 3556-3564.

SORGER, P.K., 1990. Yeast heat shock factor contains separable transient and sustained response transcriptional activators. Cell 62, 793-805.

SORGER, P.K., LEWIS, M.J. \& PELHAM, H.R., 1987. Heat shock factor is regulated differently in yeast and HeLa cells. Nature 329, 81-84.

SORGER, P.K. \& NELSON, H.C., 1989. Trimerization of a yeast transcriptional activator via a coiled-coil motif. Cell 59, 807-813.

SORGER, P.K. \& PELHAM, H.R., 1988. Yeast heat shock factor is an essential DNA-binding protein that exhibits temperature-dependent phosphorylation. Cell 54, $855-864$.

SORGER, P.K. \& PELHAM, H.R., 1987. Purification and characterization of a heat-shock element binding protein from yeast. EMBO J. 6, 3035-3041.

STEPHEN, D.W., RIVERS, S.L. \& JAMIESON, D.J., 1995. The role of the YAPI and YAP2 genes in the regulation of the adaptive oxidative stress responses of Saccharomyces cerevisiae. Mol. Microbiol. 16, 415-423.

SUGIYAMA, K., IZAWA, S. \& INOUE, Y., 2000. The Yap1-dependent induction of glutathione synthesis in heat shock response of Saccharomyces cerevisiae. $J$. Biol. Chem. 275, 15535-15540.

SWAN, T.M. \& WATSON, K., 1997. Membrane fatty acid composition and membrane fluidity as parameters of stress tolerance in yeast. Can. J. Microbiol. 43, 70-77.

SWAN, T.M. \& WATSON, K., 1999. Stress tolerance in a yeast lipid mutant: membrane lipids influence tolerance to heat and ethanol independently of heat shock proteins and trehalose. Can. J. Microbiol. 45, 472-479.

TADI, D., HASAN, R.N., BUSSEREAU, F., BOY-MARCOTTE, E. \& JACQUET, M., 1999. Selection of genes repressed by cAMP that are induced by nutrient limitation in Saccharomyces cerevisiae. Yeast 15, 1733-1745. 
TAMAS, M.J., LUYTEN, K.J., SUTHERLAND, F.C., HERNANDEZ, A., ALBERTYN, J., VALADI, H., LI, H., PRIOR, B.A., KILIAN, S.G., RAMOS, J., GUSTAFSSON, L., THEVELEIN, J.M. \& HOHMANN, S., 1999. Fps1p controls the accumulation and release of the compatible solute glycerol in yeast osmoregulation. Mol. Microbiol. 31, 1087-1104.

TAMAS, M.J., REP, M., THEVELEIN, J.M. \& HOHMANN, S., 2000. Stimulation of the yeast high osmolarity glycerol (HOG) pathway: evidence for a signal generated by a change in turgor rather than by water stress. FEBS Lett. 472, 159-165.

TANGHE, A., TEUNISSEN, A., VAN DIJCK, P. \& THEVELEIN, J.M., 2000. Identification of genes responsible for improved cryoresistance in fermenting yeast cells. Int. J. Food Microbiol. 55, 259-262.

TER SCHURE, E.G., VAN RIEL, N.A. \& VERRIPS, C.T., 2000. The role of ammonia metabolism in nitrogen catabolite repression in Saccharomyces cerevisiae. FEMS Microbiol. Lett. 24, 67-83.

THEVELEIN, J.M. \& DE WINDE, J.H., 1999. Novel sensing mechanisms and targets for the cAMP-protein kinase A pathway in the yeast Saccharomyces cerevisiae. Mol. Microbiol. 33, 904-918.

THOMAS, D.S., HOSSACK, J.A. \& ROSE, A.H., 1978. Plasma membrane lipid composition and ethanol tolerance in Saccharomyces cerevisiae. Arch. Microbiol. 117, 239-245

THOMAS, D.S. \& ROSE, A.H., 1979. Inhibitory effect of ethanol on growth and solute accumulation by Saccharomyces cerevisiae as affected by plasma-membrane lipid composition. Arch. Microbiol. 122, 49-55.

TODA, T., CAMERON, S., SASS, P., ZOLLER, M., SCOTT, J.D., MCMULLEN, B., HURWITZ, M., KREBS, E.G. \& WIGLER, M., 1987a. Cloning and characterization of $B C Y 1$, a locus encoding a regulatory subunit of the cyclic AMP-dependent protein kinase in Saccharomyces cerevisiae. Mol. Cell. Biol. 7, 1371-1377.

TODA, T., CAMERON, S., SASS, P., ZOLLER, M. \& WIGLER, M., 1987b. Three different genes in S. cerevisiae encode the catalytic subunits of the cAMPdependent protein kinase. Cell 50, 277-287.

VAN DER WESTHUIZEN, T.J., AUGUSTYN, O.P.H. \& PRETORIUS, I.S., 2000a. Geographical distribution of indigenous Saccharomyces cerevisiae strains isolated from South African vineyards in the cooler, coastal regions of the Western Cape in South Africa. S. Afr. J. Enol. Vitic. (in press)

VAN DER WESTHUIZEN, T.J., AUGUSTYN, O.P.H., KHAN, W. \& PRETORIUS, I.S., 2000b. Seasonal variation of indigenous Saccharomyces cerevisiae strains isolated from vineyards in the coastal regions of the Western Cape in South Africa. S. Afr. J. Enol. Vitic. (in press)

VAN DIJCK, P., COLAVIZZA, D., SMET, P. \& THEVELEIN, J.M., 1995. Differential importance of trehalose in stress resistance in fermenting and nonfermenting Saccharomyces cerevisiae cells. Appl. Environ. Microbiol. 61, 109-115.
VARELA, J.C., PRAEKELT, U.M., MEACOCK, P.A., PLANTA, R.J. \& MAGER, W.H., 1995. The Saccharomyces cerevisiae HSP12 gene is activated by the high-osmolarity glycerol pathway and negatively regulated by protein kinase A. Mol. Cell. Biol. 15, 6232-6245.

VISSER, W., SCHEFFERS, W.A., BATENBURG-VAN DER VEGTE, W. H. \& VAN DIJKEN, J.P., 1990. Oxygen requirements of yeasts. Appl. Environ. Microbiol. 56, 3785-3792.

VIVIER, M.A., LAMBRECHTS, M.G. \& PRETORIUS, I.S., 1997. Coregulation of starch degradation and dimorphism in the yeast Saccharomyces cerevisiae. Crit. Rev. Biochem. Mol. Biol. 32, 405-435.

WALKER, G.M., 1998. Yeast physiology and biotechnology. John Wiley \& Sons, London.

WEMMIE, J.A., SZCZYPKA, M.S., THIELE, D.J. \& MOYE-ROWLEY, W.S., 1994. Cadmium tolerance mediated by the yeast AP-1 protein requires the presence of an ATP-binding cassette transporter-encoding gene, YCF1.J. Biol. Chem. 269, 32592-32597.

WIEDERRECHT, G., SETO, D. \& PARKER, C.S., 1988. Isolation of the gene encoding the $S$. cerevisiae heat shock transcription factor. Cell 54, 841-53.

WIESER, R., ADAM, G., WAGNER, A., SCHULLER, C., MARCHLER, G., RUIS, H., KRAWIEC, Z. \& BILINSKI, T., 1991. Heat shock factor-independent heat control of transcription of the CTTl gene encoding the cytosolic catalase T of Saccharomyces cerevisiae. J. Biol. Chem. 266, 12406-12411.

WINDERICKX, J., DE WINDE, J.H., CRAUWELS, M., HINO, A., HOHMANN, S., VAN DIJCK, P. \& THEVELEIN, J.M., 1996. Regulation of genes encoding subunits of the trehalose synthase complex in Saccharomyces cerevisiae: novel variations of STRE-mediated transcription control? Mol. Gen. Genet. 252, 470-482.

WURGLER-MURPHY, S.M., MAEDA, T., WITTEN, E.A. \& SAITO, H., 1997. Regulation of Saccharomyces cerevisiae HOG1 mitogen-activated protein kinase by the PTP2 and PTP3 protein tyrosine phosphatases. Mol. Cell. Biol. 17, 1289-1297.

XUE, Y., BATLLE, M. \& HIRSCH, J.P., 1998. GPRI encodes a putative G protein-coupled receptor that associates with the $\mathrm{Gpa} 2 \mathrm{p}_{\alpha}$ subunit and functions in a Ras-independent pathway. EMBO J. 17, 1996-2007.

YUN, C.W., TAMAKI, H., NAKAYAMA. R., YAMAMOTO, K. \& KUMAGAI, H., 1997. G-protein coupled receptor from yeast Saccharomyces cerevisiae. Biochem. Biophys. Res. Commun. 240, 287-292

ZAHRINGER, H., THEVELEIN, J.M. \& NWAKA, S., 2000. Induction of neutral trehalase Nth1 by heat and osmotic stress is controlled by STRE-elements and Msn2/Msn4 transcription factors: variations of PKA effect during stress and growth. Mol. Microbiol. 35, 397-406. 